Louisiana State University

LSU Digital Commons

1970

\title{
Mother-Infant Separation in the Java Monkey (Macaca Irus).
}

Robert Stanislaus Schlottmann

Louisiana State University and Agricultural \& Mechanical College

Follow this and additional works at: https://digitalcommons.Isu.edu/gradschool_disstheses

\section{Recommended Citation}

Schlottmann, Robert Stanislaus, "Mother-Infant Separation in the Java Monkey (Macaca Irus)." (1970). LSU Historical Dissertations and Theses. 1885.

https://digitalcommons.Isu.edu/gradschool_disstheses/1885

This Dissertation is brought to you for free and open access by the Graduate School at LSU Digital Commons. It has been accepted for inclusion in LSU Historical Dissertations and Theses by an authorized administrator of LSU Digital Commons. For more information, please contact gradetd@lsu.edu. 
$71-6605$

SCHLOTTMANN, Robert Stanislaus, I937MOTHER-INFANT SEPARATION IN THE JAVA MONKEY (MACACA IRUS).

The Louisiana State University and Agricultural and Mechanical College, Ph.D., 1970 Psychology, clinical

University Microfilms, Inc., Ann Arbor, Michigan 
MOTHER-INFANT SEPARATION IN THE

JAVA MONKEY (MACACA IRUS)

\author{
A Dissertation \\ Submitted to the Graduate Faculty of the \\ Louisiana State University and \\ Agricultural and Mechanical College \\ in partial fulfillment of the \\ requirements for the degree of \\ Doctor of Philosophy \\ in \\ The Department of Psychology
}

by

Robert Stanislaus Schlottmann

B.A., Louisiana State University in New Orleans, 1962

M.S., Tulane University, 1965

August, 1970 


\section{ACKNOWLEDGMENTS}

The author is especially grateful to Dr. Bill seay, committee chairman, for his advice in the formulation of this experiment, for his invaluable assistance in its execution, and for his patience and direction in the preparation of this manuscript. The author also wishes to thank Dr. Joseph Dawson, Dr. Nathan Gottfried, Dr. Donald Hoffeld, and Dr. Perry Howard for their assistance and their service as doctoral committee members.

The author would also like to express his appreciation to Mrs. Flo Sessions, Mrs. Betty Keating, and Miss Nancy Mixon for their help in the difficult and tedious task of tabulating and compiling data, to Mrs. Mary Mevers for typing the manuscript, and to Mr. Charles Stokes and Monroe Business Machines for lending equipment used in the analysis of data.

The author would also like to take this opportunity to express his appreciation to his wife, not only for her encouragement, support, and understanding throughout the project, but also for the many hours of secretarial assistance she too devoted to its completion. 
TABLE OF CONTENTS

Page

ACKNOWLEDGMENTS . . . . . . . . . . . . . . . . . il LIST OF TABLES . . . . . . . . . . . . . . . . . iv LIST OF FIGURES. . . . . . . . . . . . . . . . . . . v ABSTRACT ......................... vi INTRODUCTION . . . . . . . . . . . . . . . . 1 METHOD . . . . . . . . . . . . . . . . . 7 RESULTS. . . . . . . . . . . . . . . . . . 16 DISCUSSION . . . . . . . . . . . . . . . . . . 36 REFERENCES ........................... 43 APPENDICES . . . . . . . . . . . . . . . . . . 46 Appendix I. . . . . . . . . . . . . . 47 Appendix II . . . . . . . . . . . . . . 52 Appendix III. . . . . . . . . . . . . . 55 VITA . . . . . . . . . . . . . . . . . . 60 


\section{LIST OF TABLES}

Table

Page

1. Combination categories used in assessing immediate effects of separation and reunion . . . . . 17 
LIST OF FIGURES

Figure

Page

1. Apparatus (top view) . . . . . . . . . . 8

2. Infant-infant interaction. Immediate overall effects of separation. . . . . . . . . . . 18

3. Infant-infant non-specific contact. Immediate effect of separation . . . . . . . . . . . .

4. Infant non-social object-directed behavior. Immediate effect of separation. . . . . . . . . 20

5. Infant-infant approach, withdraw, and ear-flip threat for A and SM groups combined. Period-wide effects. . . . . . . . . . . . . . . . .

6. Infant-infant non-specific contact. Period-wide effects. . . . . . . . . . . . . . . . .

7. Infant non-social self-play, manual manipulation, and vocal coo for $A$ and SM groups combined. Periodwide effects . . . . . . . . . . . . . . .

8. Infant self-mouthing and non-social oral exploration. Period-wide effects of separation. . . . . . . .

9. Immediate overal1 effects of reunion . . . . . . 27

10. Infant-infant non-specific contact. Immediate effect of reunion. . . . . . . . . . . . . . .

11. Infant-infant passive interaction. Immediate effect of reunion. . . . . . . . . . . . .

12. Infant-infant clasp-pu11. Period-wide effects . .

13. Infant-mother cling, ventral contact, and nipple contact. Period-wide effects of reunion . . . . . 32

14. Mother-infant grooming. Period-wide effects . . . 33

15. Infant-mother cling, ventral contact, and nipple contact. Period-wide effects of original vs. reversed home cage return of mothers . . . . . . . 
ABSTRACT

Twelve mother-infant pairs of Macaca irus monkeys were divided into 6 groups of 2 mother-infant pairs each. During a 3-week separation period, infants in 2 groups received substitute mothering while infants in another 2 groups did not. Infants in the remaining 2 groups were separated and immediately reunited with mothers. During reunion, mothers in half of the groups were returned to their original home cages, and mothers in the remaining half were returned to identical but spatially reoriented home cages.

During separation, infant playing and related behavior decreased. The effects could not be attributed to the traumatic process of forceful removal of mothers since separation and immediate return of mothers had a minimal effect on infant behavior. During reunion, infants responded differentially to their own mothers regardless of location of return. Although most behaviors returned to pre-separation levels, there was an indication of prolonged disturbance in the form of an intensified mother-infant relationship for 3-week separated animals. Substitute mothering, although it did not alleviate the debilitating effects of separation, did facilitate recovery in reunion. Species differences in the reaction to maternal separation were discussed. 


\section{INTRODUCTION}

Bowlby (1958a) states that the child's tie to its mother is the result of a number of component instinctual responses such as sucking, clinging, following, crying, and smiling which produce a reciprocal reaction from its mother. These component instincts are believed to have arisen in evolution and are necessary for survival since the human neonate is completely helpless and dependent upon its mother to fulfill its physiological needs. When the young child is separated or otherwise deprived of its mother or permanent motherfigure as in the case of death, hospitalization, or repeated rejection, a severe emotional reaction occurs (Bowlby, 1952; 1960a, b; 1961a, b). The initial reaction is that of protest characterized by separation anxiety, which is believed to be the immediate consequence of activation of instinctive response systems without termination. If separation continues, the child goes through a stage of despair characterized by grief and mourning. Eventually, a detachment stage may occur in which the child tries to defend against anxiety. These responses are believed to be biologically basic and no different from the response of adults to loss of love object. If maternal separation occurs when a child is between the ages of six months and five or six years, and is sufficiently prolonged or severe, it is believed to predispose him to delinquent, depressive, or other psychiatric disorders in later years.

In attempting to test Bowlby's theories, some investigators 
have found that maternal separation is indeed stressful to the young child and that, following reunion with the mother, separated children often behave negatively and aggressively (Robertson, 1955; Heinicke, 1956). Other investigators, however, have questioned whether such results are due indeed to maternal separation or whether they are due to environmental deprivation characteristic of many institutional settings (Wooton, 1966; 0'Connor, 1956). Stott (1956) maintains that it is not separation per se that is the crucial variable, but the lack of maternal loyalty. Others have questioned the wisdom of using a single variable, such as the loss of mother or permanent mother-figure, to explain the diversity in nature of the adverse effects and the variability in degree of damage (Prugh and Harlow, 1966; Andry, 1966). Equally detrimental to Bowlby's views is the finding that intelligence test scores, which decrease during separation, may recover following the mother's return, thus questioning the degree of permanence of adverse effects (Clarke and Clarke, 1959). Furthermore, it j.s becoming increasingly apparent that maternal separation may not predispose a child to delinquency in 1ater years (Naess, 1959; Lewis, 1959; Andry, 1966; and Bowlby, Ainsworth, Boston, and Rosenbluth, 1956).

Such findings have not, however, led Bowlby and his followers to change their position in any material way. The relationship between antecedent and consequent conditions is indeed complex, and the effects of maternal separation depend upon many other factors as well, such as the length of separation, the age of the child at 
separation, the nature of the mother-child relationship prior to separation, and so forth (Ainsworth, 1966). However, maternal separation theorists now state that the adverse effects may be more readily reversible than previously thought, and they no longer maintain that children who experience maternal separation commonly develop psychopathic and affectionless characters later in life (Bowlby et ai., 1956; Bowlby, 1958b; Ainsworth, 1966). It has also been pointed out that there are enormous problems in conducting research on human children in this area, and the importance of combining clinical, psychometric, and experimental approaches to the problem has been emphasized (Bowlby, 1952).

The variables affecting the mother-infant tie (Harlow and Zimmerman, 1959; Bowlby, 1961a) and the overt response to loss of love object (Bowlby, 1961b) are believed to be similar in humans and other primates, and several investigators have studied the effects of maternal separation in monkeys. Using an apparatus in which mother-infant pairs of rhesus monkeys (Macaca mulatta) were housed on opposite ends of a play area in which only infants were allowed access, Seay, Hansen, and Harlow (1962) and Seay and Harlow (1965) found that maternal separation is extremely stressful to rhesus infants. When their mothers were not available, there was much crying (coolng vocalization) and a reduction in many complex social behaviors such as infant playing. Mothers reacted violently to being separated from their infants and attempted to maintain 
physical contact with them. When the mothers were returned, there was an initial but temporary increase in infant-mother and motherinfant positive behaviors.

Basically similar results were obtained by Spencer-Booth and Hinde (1967), also using the rhesus macaque, and by Kaufman and Rosenblum (1967), using the pigtail (Macaca nemestrina). The monkeys in these studies were maintained in a complex group situation, and removal of mothers did not involve separation from other monkeys. Some of the infants in these investigations showed signs of prolonged disturbance even after several months following the mother's return in contrast to the studies of Seay and Harlow (1965) and Seay et a1., (1962).

Rosenblum and Kaufman (1968) found that bonnet macaque (Macaca radiata) infants living in a group situation do not show the severe disturbance following maternal separation that seems to characterize the reactions of rhesus and pigtail monkeys. When their mothers were removed, the infants appeared agitated initially, but quickly recovered. They showed only slight decreases in complex social behaviors such as social playing. The investigators attributed their failure to show debilitating effects to the permissive behavior of bonnet mothers who frequently allow other adults to explore and manipulate newborn infants almost immediately after birth. As a result, these infants become autonomous early and establish social relationships with adults other than their natural mother. 
However, pilot work conducted by these investigators indicates that either bonnet or pigtail infants, when placed with strange adults, may barely survive a single day of exposure.

In the present investigation, an attempt was made to determine the generality of the effects of maternal separation.in a different species of macaque, the Java monkey (Macaca irus). Results were compared with the rhesus data obtained in previous studies conducted by Seay et al., (1962) and Seay and Harlow (1965) using a similar apparatus and procedure. Comparisons were also made with data recently obtained by Preston, Baker, and Seay, (in press) on the patas monkey (Erythrocebus patas). These investigators, who also used a similar apparatus and procedure, found that patas infants show the usual decline in play behavior during separation. In reunion, however, there was an increase in infant peer interaction rather than an intensification of the mother-infant relationship as observed in macaques .

In addition, it was felt that the consequences of placing Java infants with unfamiliar adult females of the same species would not be fatal, and the present investigation attempted to determine whether differential effects are produced by providing infants with substitute mothers during the separation period. A third objective was to determine whether the adverse effects of maternal separation are due to the absence of the mother or whether such effects are due to the process of forceful separation itself. A fourth and final 
objective of the present investigation was to determine whether Java infants are able to discriminate and respond differentially to their own mothers following a three-week separation period if the mothers axe returned to identical but spatially reoriented home cages, Infant-mother and mother-infant specificity had previously been observed by Jensen and Tolman (1962) in $\underline{M}$. nemestrina following brief separations (up to one hour), and an early study by Spence (1937) indicated that chimpanzee mothers could recognize and respond differentially to their own infants even after separations of six months or more. 
METHOD

Subjects.--Twelve mother-infant pairs of $\underline{M}$. irus monkeys were divided into six groups of two mother-infant pairs each according to time of birth of infants. At the time of separation, infant ages ranged from 208 to 255 days. The mean within-group age difference was 25 days with the maximum for any group being 38 . Of the six groups employed, two contained a female-female infant pair (Groups $A_{1}$ and $S_{1}$ ), two contained a male-male infant pair (Groups $S M_{2}$ and $C_{2}$ ), and two a male-female infant pair (Groups $A_{2}$ and $C_{1}$ ). All infants were laboratory born and a11 mothers were feral animals.

Apparatus.--The apparatus is shown in Figure 1 and was constructed of galvanized, flattened, expanded metal on an angle-iron frame. It consisted of two $36 \times 27 \times 42$ in. home cages attached on opposite ends of a $60 \times 27 \times 42$ in. play area. The play area was further subdivided by a removable pane1, and access to it was provided for infants only by $3.5 \mathrm{sq}$. in. openings. Each home cage was equipped with a feeder, water bottle, wall-size front door and transport door. The apparatus stood on legs $30 \mathrm{in}$, above the floor.

Procedure.--Data collection was divided into three, 3-week periods. The first 3 weeks were the same for all groups, and consisted of baseline observation of mothers and infants. In order to test the generality of the effects of maternal separation in the Java monkey, the second 3-week period for Groups $A_{1}$ and $A_{2}$ consisted of 
REMOVABLE PANEL

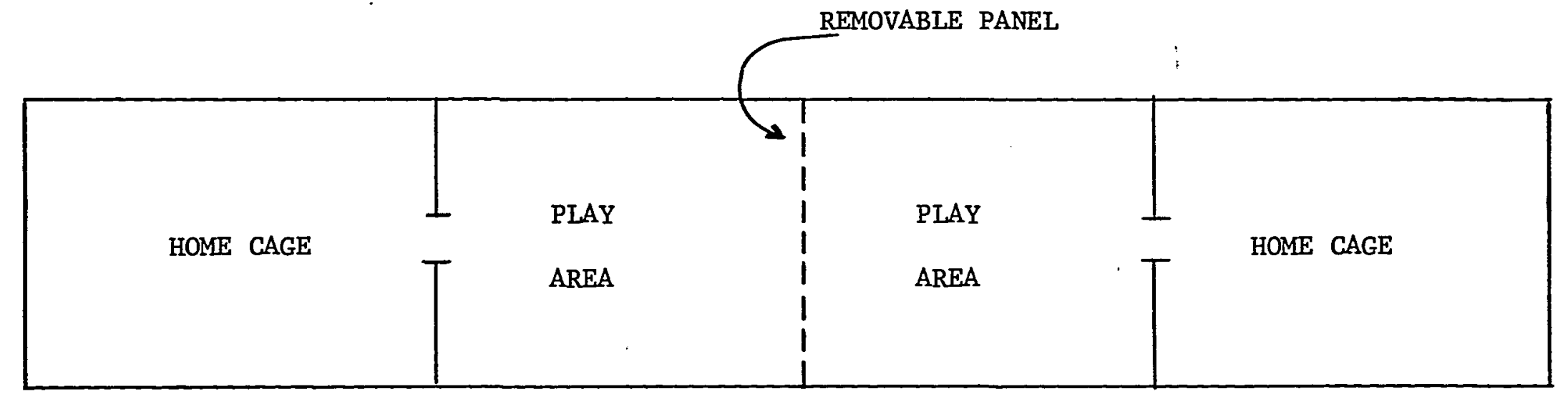

Fig. 1. Apparatus (top view). 
observation of infants whose mothers had been removed to another part of the bullding. For Groups $\mathrm{SM}_{1}$ and $\mathrm{SM}_{2}$, the second 3-week period consisted of observation of Infants with unfamiliar adult females following removal of real mothers to determine whether differential effects are produced by providing infants with substitute mothers during separation. For Groups $C_{1}$ and $C_{2}$, the second 3-week period consisted of observation of infants and real mothers, following the removal and Immediate return of the real mothers, to determine whether the adverse effects of maternal separation are due to absence of the mother or to the process of forceful separation itself.

The third 3-week period consisted of observation of mothers and infants following return of the mothers (Groups $A_{1}$ and $A_{2}$ ), removal of substitute mothers and return of real mothers (Groups $\mathrm{SM}_{1}$ and $\mathrm{SM}_{2}$ ), or removal and immediate return of mother-infant pairs (Groups $\mathrm{C}_{1}$ and $\mathrm{C}_{2}$ ). Mothers in ha1f of the groups (Groups $\mathrm{A}_{1}, \mathrm{SM}_{1}$, and $\mathrm{C}_{1}$ ) were returned to their original home cages, and mothers in the remaining groups (Groups $\mathrm{A}_{2}, \mathrm{SM}_{2}$, and $\mathrm{C}_{2}$ ) were returned to cages identical to their own but previously occupied by the other motherinfant pair of the same group in order to determine whether infants are able to recognize and respond differentially to their own mothers following a 3-week separation period.

The separation procedure involved the simultaneous placement of metal plates by two investigators between each home cage and the play area in such a way as to prevent infants from running to their 
mothers. A small transport cage was then placed on the edge of each home cage, and guillotine doors were raised to allow mothers to enter. The metal plates blocking the infants' access to home cages were then removed. The introduction of substitute mothers and the return of real mothers to home cages were also done by means of transport cages. Mothers were simultaneously released by two investigators while their infants were in the play area and the panel removed. The panel subdividing the play area was removed for approximately one-half hour per day, 4 days per week, during which time data collection was undertaken. Data collection consisted of eight, 15 min. sessions per week on each mother-infant pair throughout the 9-week period. A modification of the symbol checklist developed by Hansen (1966) at the University of Wisconsin Primate Laboratory was used for this purpose. Symbols representing many different behaviors were recorded on $8.5 \times 11$ in. data sheets consisting of two columns of ten rows each. Each row was further subdivided with the upper half being used to record the behavior of mothers and the bottom half the behavior of infants. Mother and infant behavior was scored simultaneously as it has previously been shown that one observer is able to score two animals at the same time reliably and efficiently (Thorne, Schlottmann, and Seay, 1969). A tape recorded voice counted from zero to 60 with $15 \mathrm{sec}$. intervals between each number to indicate when entries were to be made on the next row. The maximum score for each behavior occurring in a $15 \mathrm{sec}$. Interval was one. Therefore, the maximum score for a behavior category in the $15 \mathrm{~min}$. 
session was 60 . In recording data, observers were seated on stools approximate $1 \mathrm{y} 4 \mathrm{ft}$. from the test apparatus and in full view of the Ss. Data sheets were held in place by means of a clipboard. The actor and recipient animal were indicated by a system of color coding and position of score on the data sheet.

The following is a rist of behaviors scored and their definitions. Two observers participated in data collection and estimates of interobserver reliability obtained by means of Pearson productmoment correlation coefficients are listed after each definition. In one instance, no correlation coefficient is given since the behavior occurred very infrequently during reliability sessions. Al1 reliability coefficients are based on sessions conducted by the two observers during acquisition of developmental data for another project prior to initiation of the present study.

\section{Infant-infant behaviors}

$\begin{array}{ll}\text { Approach } & \text { Oriented movement of } 1 \mathrm{ft} . \text { or more toward } \\ & \text { another infant }(.781) \text {. } \\ \text { Withdraw } & \text { Oriented movement of } 1 \mathrm{ft} \text {. or more away } \\ & \text { from another infant }(.825) . \\ \text { Non-contact } & \text { Highly active, oriented movement toward } \\ \text { play } & \text { or away from another infant involving two } \\ & \text { or more directional turns. Also includes } \\ & \text { bee-line mock attack of three or more body } \\ & \text { lengths and rapid bouncing in place with } \\ & \text { orientation toward the other infant (.853). }\end{array}$




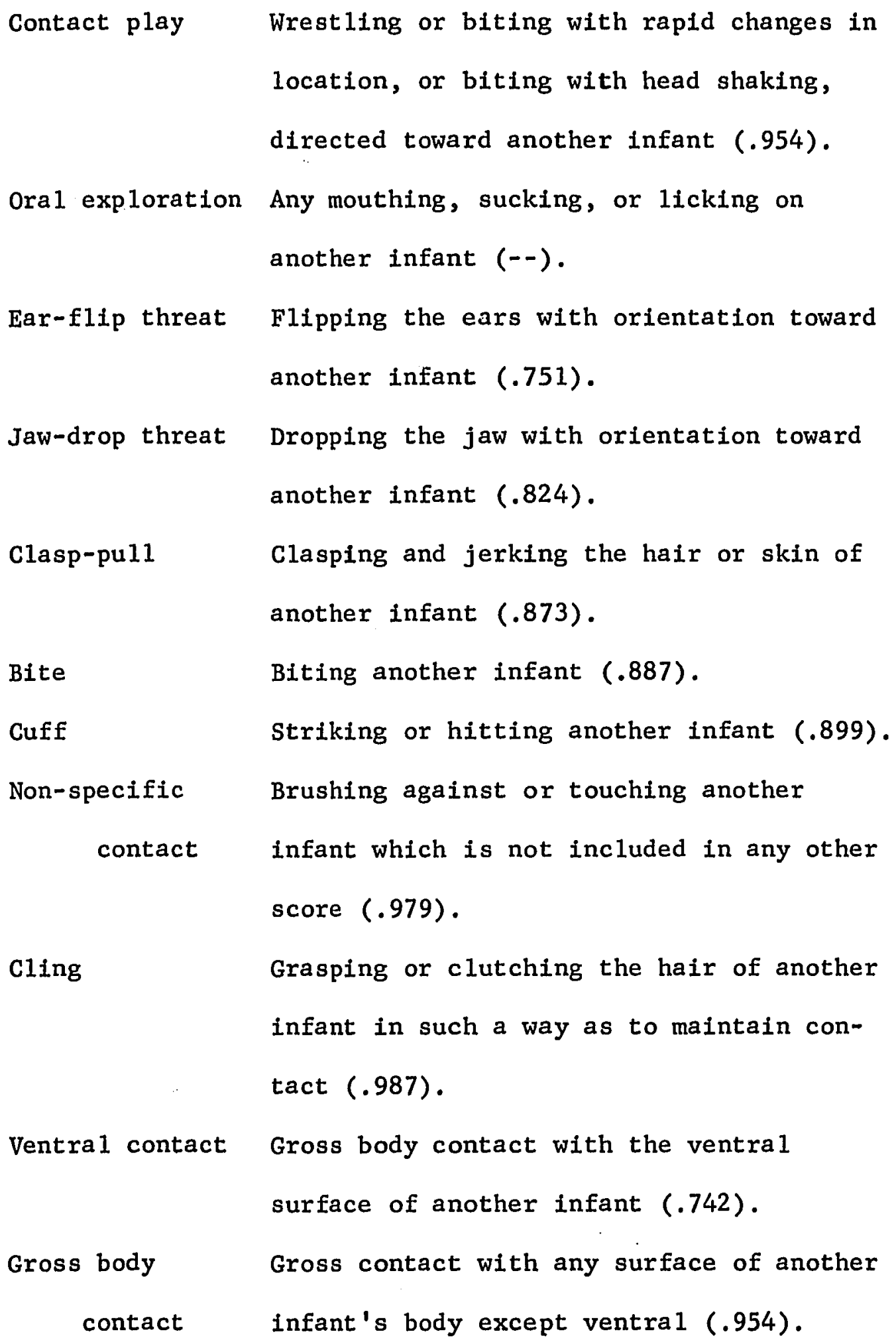

Infant non-social behaviors

Vocal screech High-pitched screaming (.937). 
Vocal coo

Vocal yip

Self-mouthing

Ora1 exploration

Manual manipu-

lation

Self-play
Tonal vocalization resulting in ooo-ooh sound $(.894)$

Short, abrupt, high-pitched sound (.696). Any mouthing or oral manipulation of infant's own body $(.930)$.

Mouthing or licking cage or other inanimate object $(.894)$.

Manipulating or exploring the cage or other Inanimate object with the hand (.774). Any behavior meeting the activity criterion of non-contact play, but without social orientation $(.747)$.

Infant-mother behaviors

Ventral contact Gross body contact with the ventral

cling surface of the mother (.997). Grasping or clutching the hair of the mother in such a way as to maintain contact $(.992)$.

Nipple contact Mouthing, sucking, or holding the nipple of the mother in the mouth $(.979)$. Non-specific Brushing against or touching the mother contact which is not included in any other score $(.969)$

Approach Oriented movement of $1 \mathrm{ft}$. or more toward the mother $(.784)$. 
Gross body Gross contact with any surface of the contact mother's body except ventral (.917).

Infant-other mother behaviors

Non-specific

As above, but directed or oriented toward contact adult female other than infant's own mother (.864).

Withdraw As above, but movement is away from adult female other than infant's own mother $(.548)$

Mother-infant behaviors

Groom Spreading and picking at fur of infant $(.973)$

Embrace Encircling or partly encircling the body of infant with one or both arms (.970).

Mother-other infant behaviors

Jaw-drop threat As above, but directed by adult female toward infant other than her own (.938).

Approach As above, but movement is by adult female toward infant other than her own (.901).

Mother non-social behaviors

Lipsmack Smacking the lips rapidly with orientation toward the observer or without apparent orientation (.972). 
Jaw-drop threat As above, but directed toward observer (.990).

Statistical analysis.--The mean score per session in each of the three experimental periods was calculated for each infant for each category of infant-infant and infant non-social behavior. Since mothers were not present for A groups during period two, the mean score per session for mother and mother-related behaviors was calculated for" periods one and three. These data were then analyzed using repeated measures analysis of variance and relevant comparisons were made using orthogonal coefficients. In assessing the immediate effects of separation, data from the last session of period one and the first session of period two were used instead of the mean score per session for each period. Similarly, data from the last session of period one and the first session of period three were used in assessing the immediate effects of reunion.

The behavior of and toward substitute mothers in SM groups was compared to the behavior of and toward real mothers in $\mathrm{C}$ groups during period two. The mean score per session for each category of mother and mother-related behaviors was calculated and analyzed by means of $\underline{t}$ tests. The .05 level of significance was used in all of the above tests. 


\section{RESULTS}

Immediate effects of separation.--Inspection of the data on initial changes in which scores for single sessions rather than period-wide means were used revealed that most behaviors did not occur frequently enough to warrant analysis. It was therefore decided to combine the data into broader categories by adding the scores for each $\underline{\mathrm{S}}$ across several behaviors that logically seemed to be related. The resulting combination categories and their components are shown in Table 1. Infant-infant non-specific contact was also analyzed due to the high frequency of occurrence of this behavior.

The initial reaction of infants to separation was characterized by a significant decrease in active and passive interaction over al1 groups (Figure 2). There was a tendency for infant distress vocalization to increase, but the effect was not statistically significant. Non-specific contact (Figure 3) and non-social objectdirected behavior (Figure 4) decreased sharply in the SM groups while showing only slight changes in the A groups, and the differential effects were statistically significant in both cases.

Period-wide effects of separation.--Analysis of period-wide effects of separation revealed that the brief separation experienced by infants in the $C$ groups produced virtually no change in behavior other than a significant increase in infant-infant contact play. In contrast, infants in the experimental groups (A and SM 
TABLE 1

COMBINATION CATEGORIES USED IN ASSESSING IMMEDIATE EFFECTS OF SEPARATION AND REUNION

\begin{tabular}{ll}
\hline Combination Category & Specific Behaviors Combined \\
\hline Inf-inf active interaction & $\begin{array}{l}\text { Non-contact play, approach, contact play, ear-flip threat, } \\
\text { jaw-drop threat, clasp-pul1, bite, cuff }\end{array}$ \\
$\begin{array}{l}\text { Inf-inf passive interaction } \\
\text { Inf distress vocalization }\end{array}$ & Vocal screech, vocal coo \\
$\begin{array}{l}\text { Inf non-soc object-directed } \\
\text { behavior }\end{array}$ & Oral exploration, manual manipulation \\
$\begin{array}{l}\text { Inf-mot positive behavior } \\
\text { Ventral contact, cling, nipple contact, non-specific } \\
\text { contact, approach, gross body contact }\end{array}$ \\
\hline
\end{tabular}




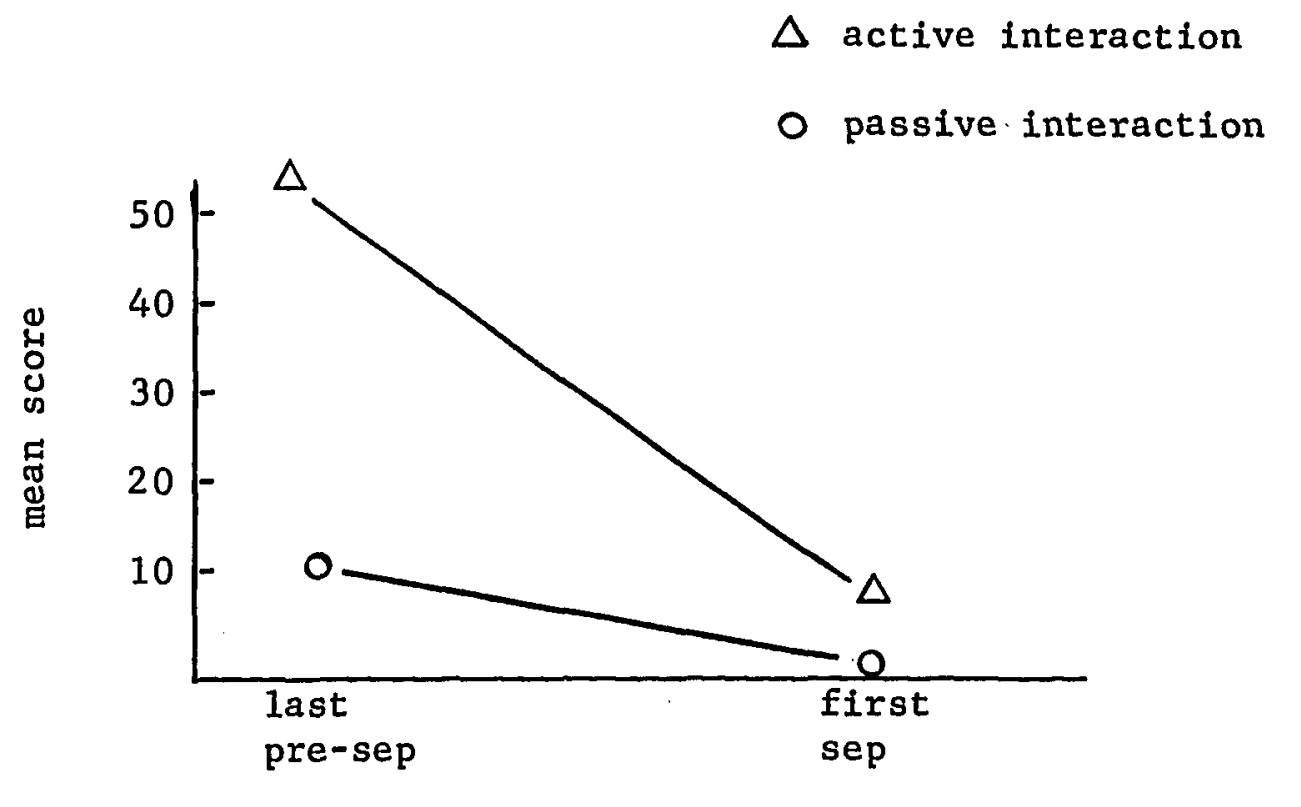

Fig. 2. Infant-infant interaction. Immediate overall effects of separation. 


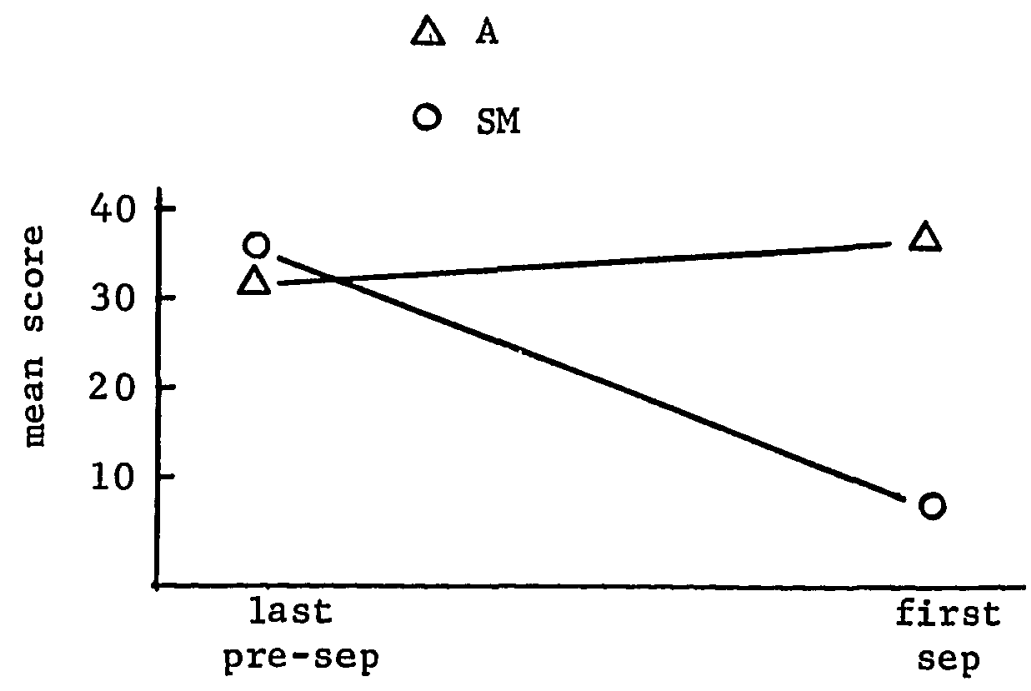

Fig. 3. Infant-infant non-specific contact. Immediate effect of separation. 


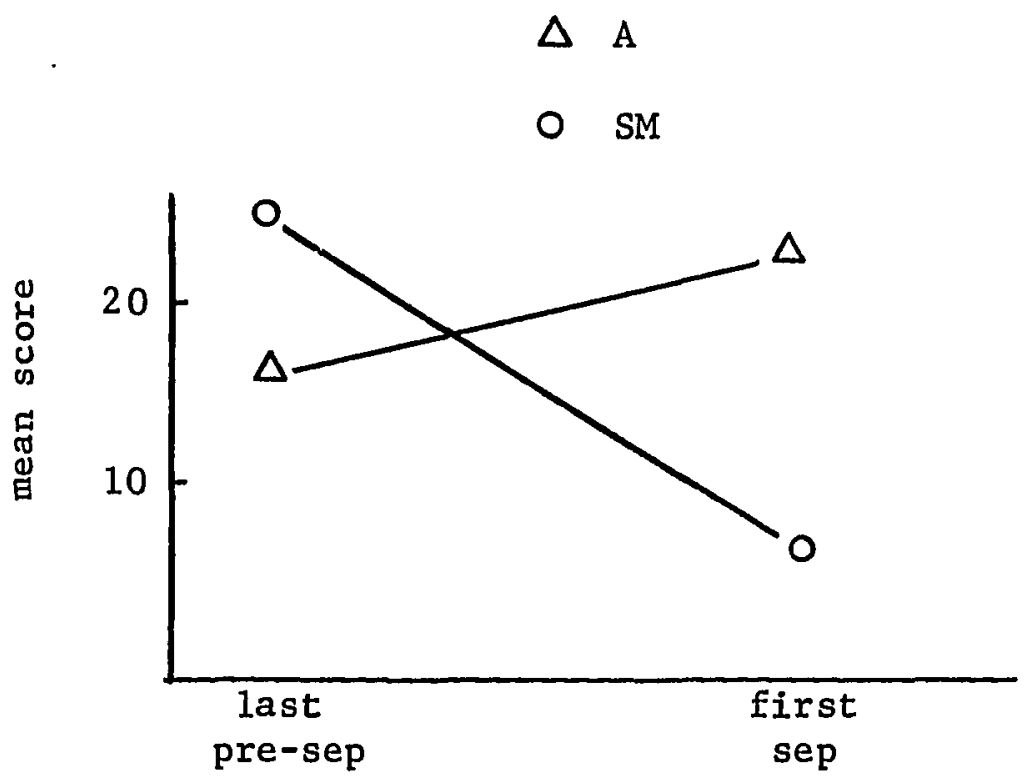

Fig. 4. Infant non-social object-directed behavior. Immediate effect of separation. 
groups combined) showed very pronounced decreases during the separation period in infant playing and related behaviors. Statistically significant decreases were found in infant-infant approaches, withdraws, contact and non-contact plays, ear-flip and jaw-drop threats, clasppul1s, bites, cuffs, and non-specific contacts (see Figure 5). The decrease in non-specific contact was significantly greater for infants in the SM group than for infants in the A groups (Figure 6). Infants in the experimental groups also showed significant changes during separation in some non-social behaviors as we11. Selfplaying decreased significantly while manual manipulation and vocal coo increased (Figure 7). Significantly different reactions to separation between the A and SM groups were found for self-mouthing and non-social oral exploration. Infants in the A groups showed a decrease in self-mouthing and an increase in non-social oral exploration during separation, while infants in the SM groups showed only slight changes in these behaviors (Figure 8). Vocal yip showed a significant decrease during separation only when the data over al1 groups was included.

Some additional significant effects during separation (and also during reunion) resulted from differences in the sexual composition of groups. Sex differences resulted in pre-separation differences between groups for some behaviors. Corresponding differential changes from one period to another were found in some instances since the lower limit of zero prevented a group with a low frequency of occurrence for a particular behavior from showing a marked decrease in 

a approach
o withdraw
$\Delta$ ear-flip threat

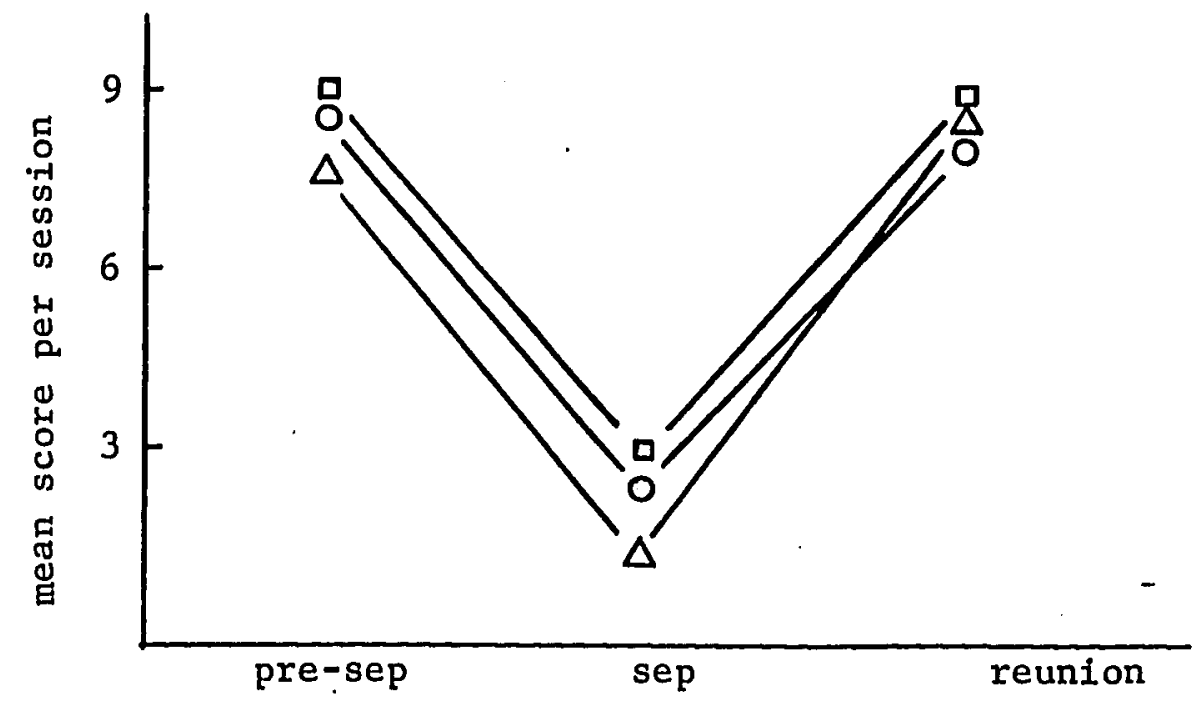

Fig. 5. Infant-infant approach, withdraw, and ear-flip threat for $A$ and SM groups combined. Periodwide effects. 


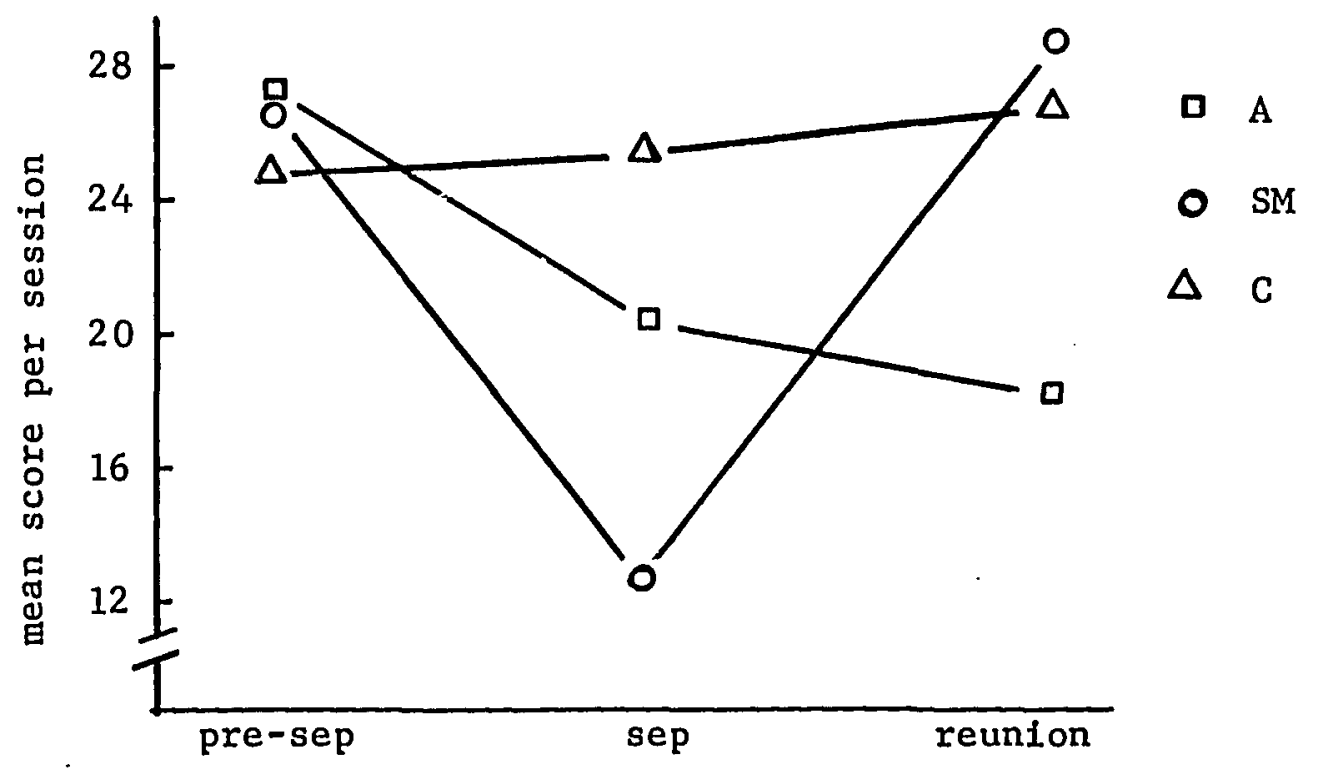

Fig. 6. Infant-infant non-specific contact. Period-wide effects. 
a self-play

- manual manipulation

$\Delta$ vocal coo

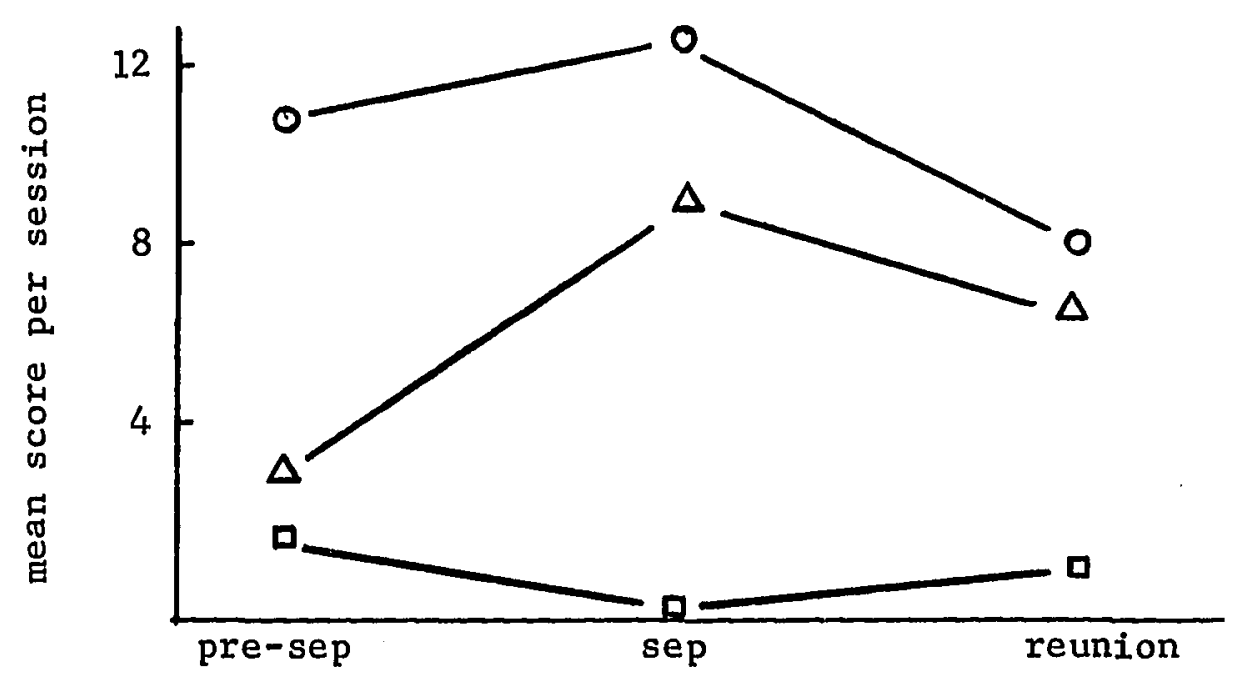

Fig. 7. Infant non-social self-play, manual manipulation, and vocal coo for $A$ and $S M$ groups combined. Period-wide effects. 


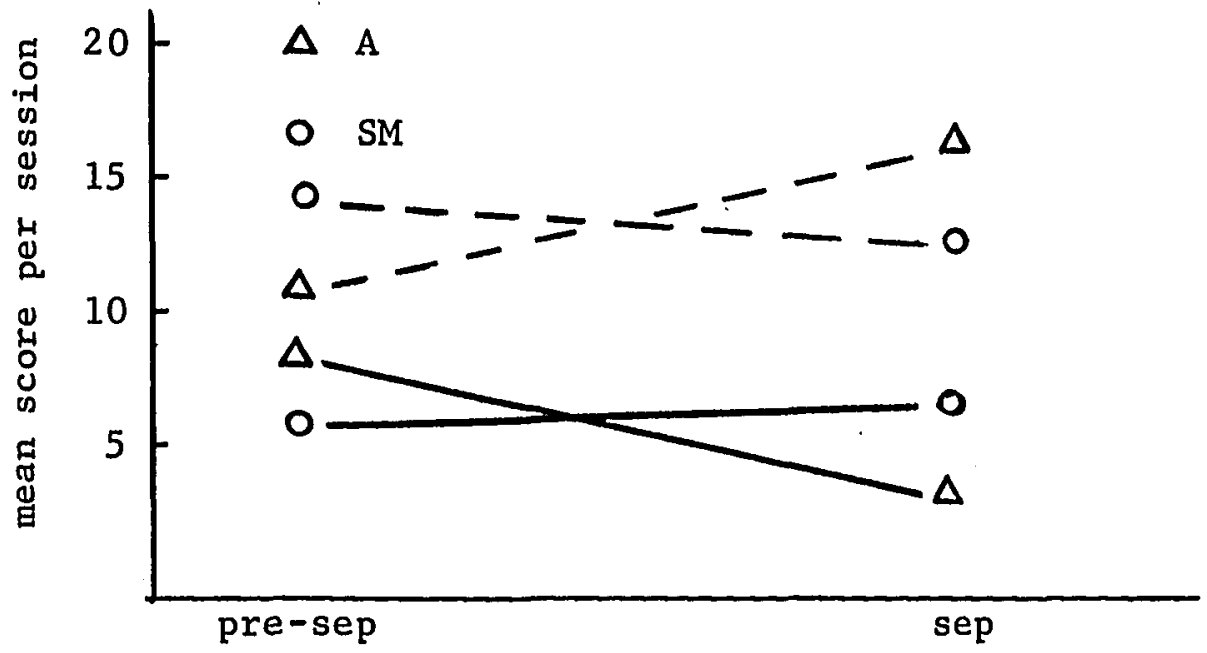

Fig. 8. Infant self-mouthing (solid lines) and non-social oral exploration (broken lines). Period-wide effects of separation. 
that behavior. Therefore, effects due to sex differences between groups had to be taken into consideration in the interpretation of statistically significant results.

Immediate effects of reunion.--Compared to the last preseparation sesstion, the immediate reaction to reunion was characterized by a pronounced increase in mother-infant interactions and a pronounced decrease in infant peer-directed behaviors. Significant overall initial increases were found for mother-infant and infant-mother positive behavior. Conversely, significant overall initial decreases were found for infant-infant active interaction, non-specific contact, and non-social object-directed behavior (Figure 9). The initial decrease in infant-infant non-specific contact was significantly greater for infants in the experimental groups (Figure 10). For infant-infant passive interaction, a statistically significant differential reaction was found between the A and SM groups. Compared to the last pre-separation session, infants in the A groups showed an initial increase in this behavior during reunion, while infants in the SM groups showed an initial decrease (Figure 11).

Period-wide effects of reunion.--Few period-wide differences in infant-infant and infant non-social behavior were found during reunion between the groups as the behavior of infants in the experimental groups tended to return to pre-separation levels (see Figure 5). There was a significant difference in reunion between the 


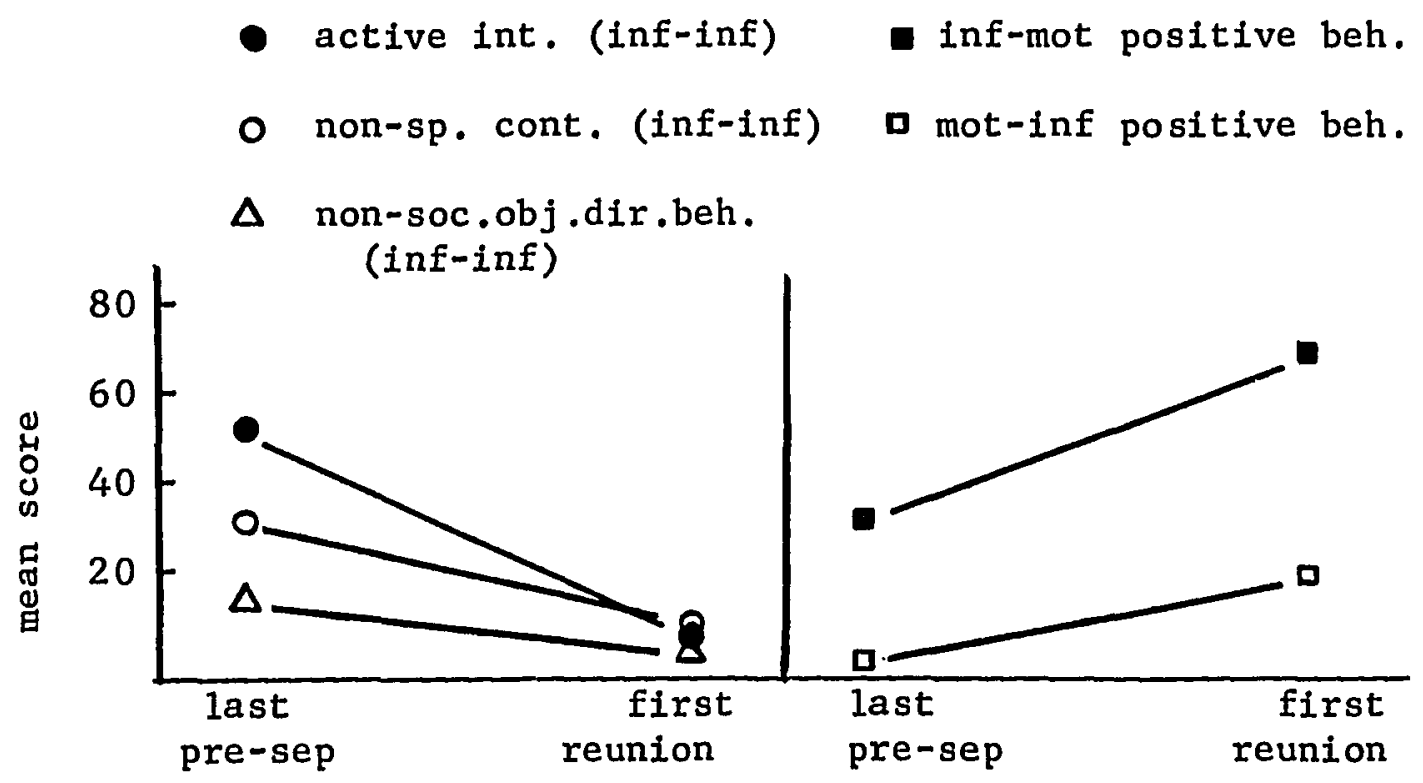

Fig. 9. Immediate overall effects of reunion. 


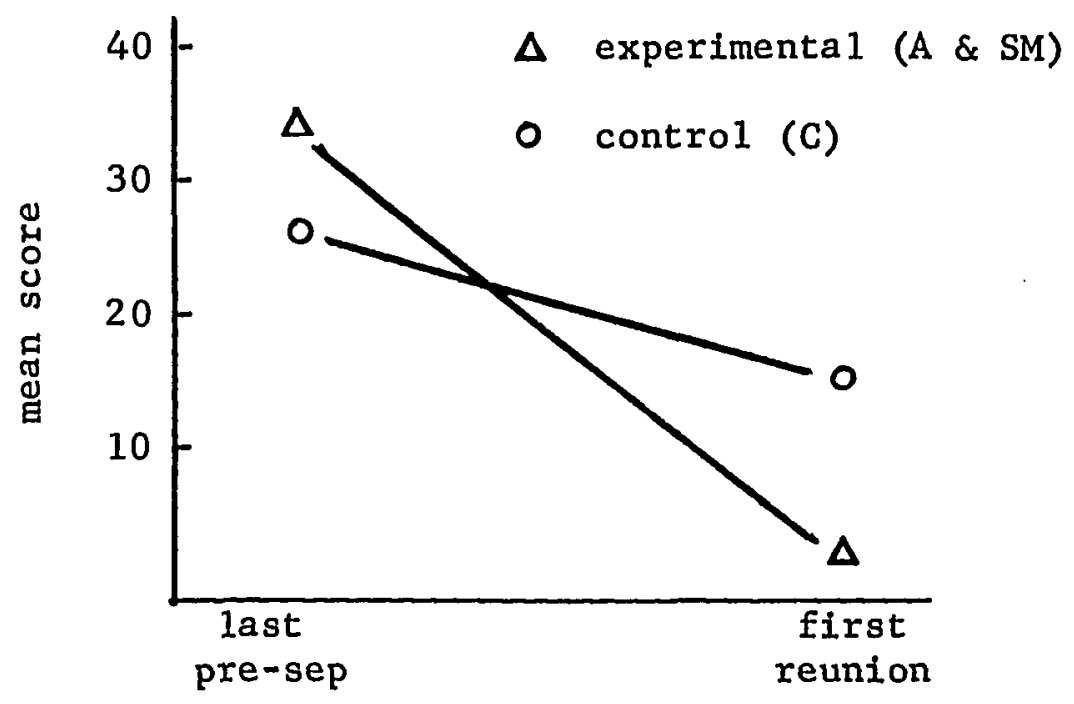

Fig. 10. Infant-infant non-specific contact. Immediate effect of reunion. 


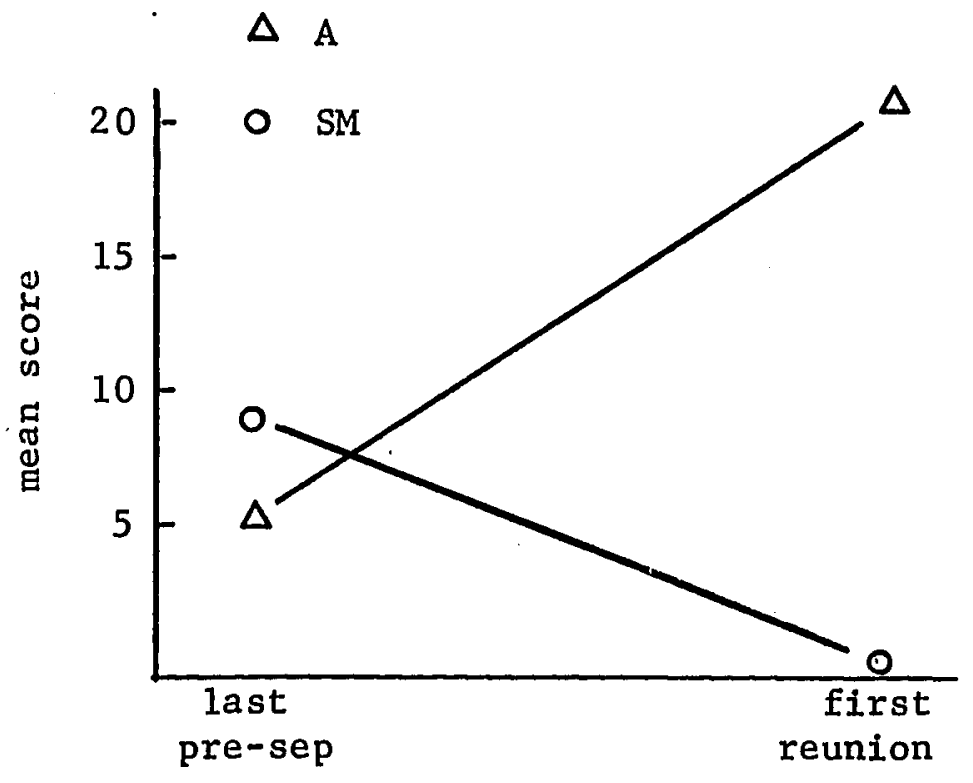

Fig. 11. Infant-infant passive interaction. Immediate effect of reunion. 
experimental and control groups in infant-infant clasp-pull, a behavior which increased slightly in reunion but did not return to its pre-separation level (Figure 12). There was also a significant difference in reunion between the $A$ and SM groups for infant-infant non-specific contact. This behavior returned to its pre-separation level for the SM groups, but continued to decrease in reunion for the A groups (Figure 6).

Analysis of period-wide effects of reunion also revealed that the initial overal1 intensification of the mother-infant relationship continued throughout reunion for the $\underline{S} s$ in the experimental groups. Infant-mother ventral contact, cling, and nipple contact showed a significantly greater increase in reunion for the experimental than for the control groups. Also, infants in the A groups showed significantly greater increases in these behaviors than infants in the SM groups (Figure 13). The experimental groups combined also showed a significant differential change in mother-infant grooming during reunion (Figure 14). Compared to pre-separation levels, mothers in the experimental groups groomed their infants more during reunion while mothers in the control groups groomed their infants less. The return of mothers to reversed home cage locations resulted in a significant overal1 increase in infant-mother ventral contact, cling, and nipple contact (Figure 15). When only the data from the experimental groups was considered, the effect was significant only for infant-mother ventral contact and cling. 


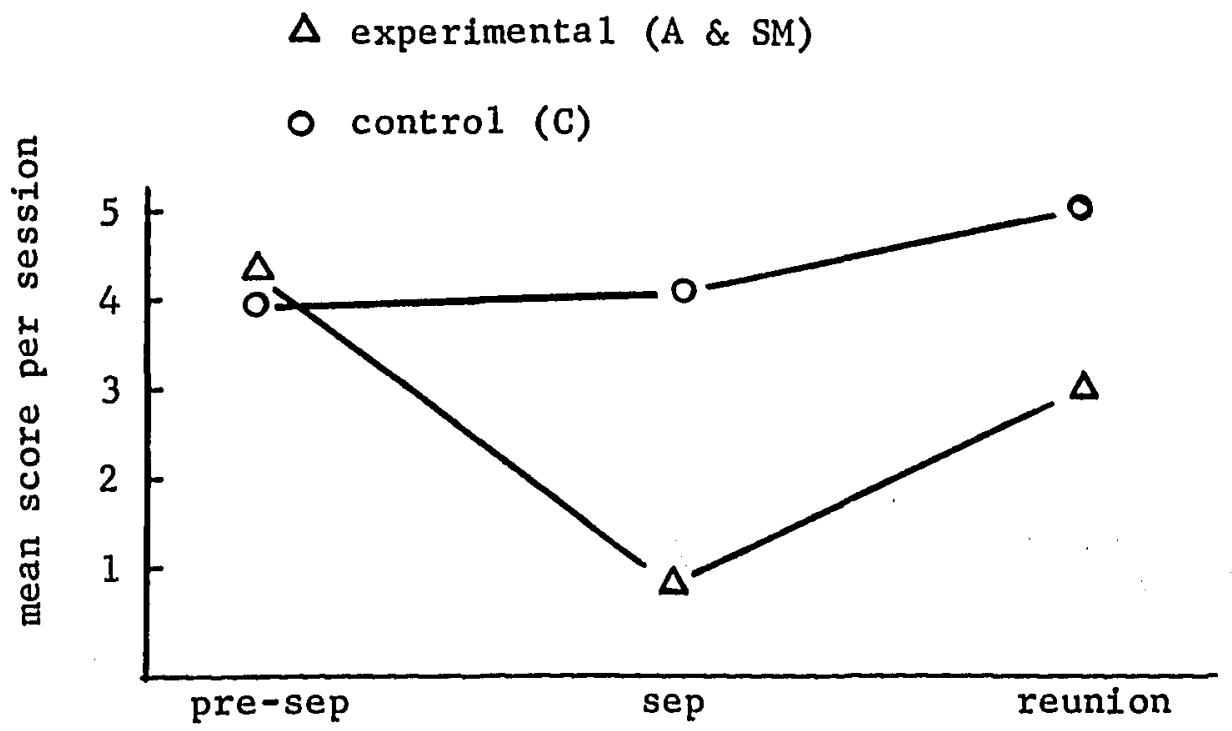

Fig. 12. Infant-infant clasp-pul1. Periodwide effects. 


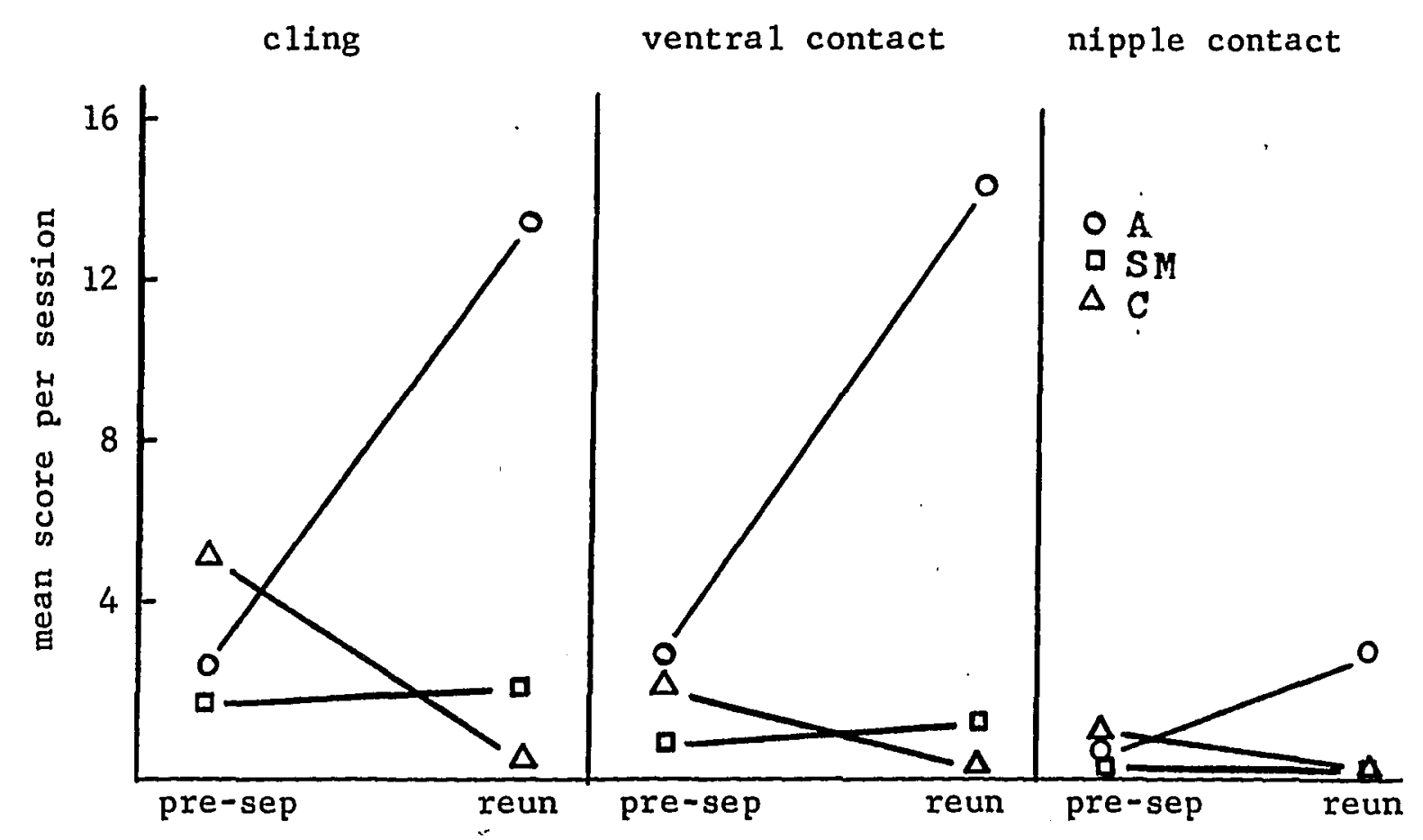

Fig. 13. Infant-mother cling, ventral contact, and nipple contact. Period-wide effects of reunion. 


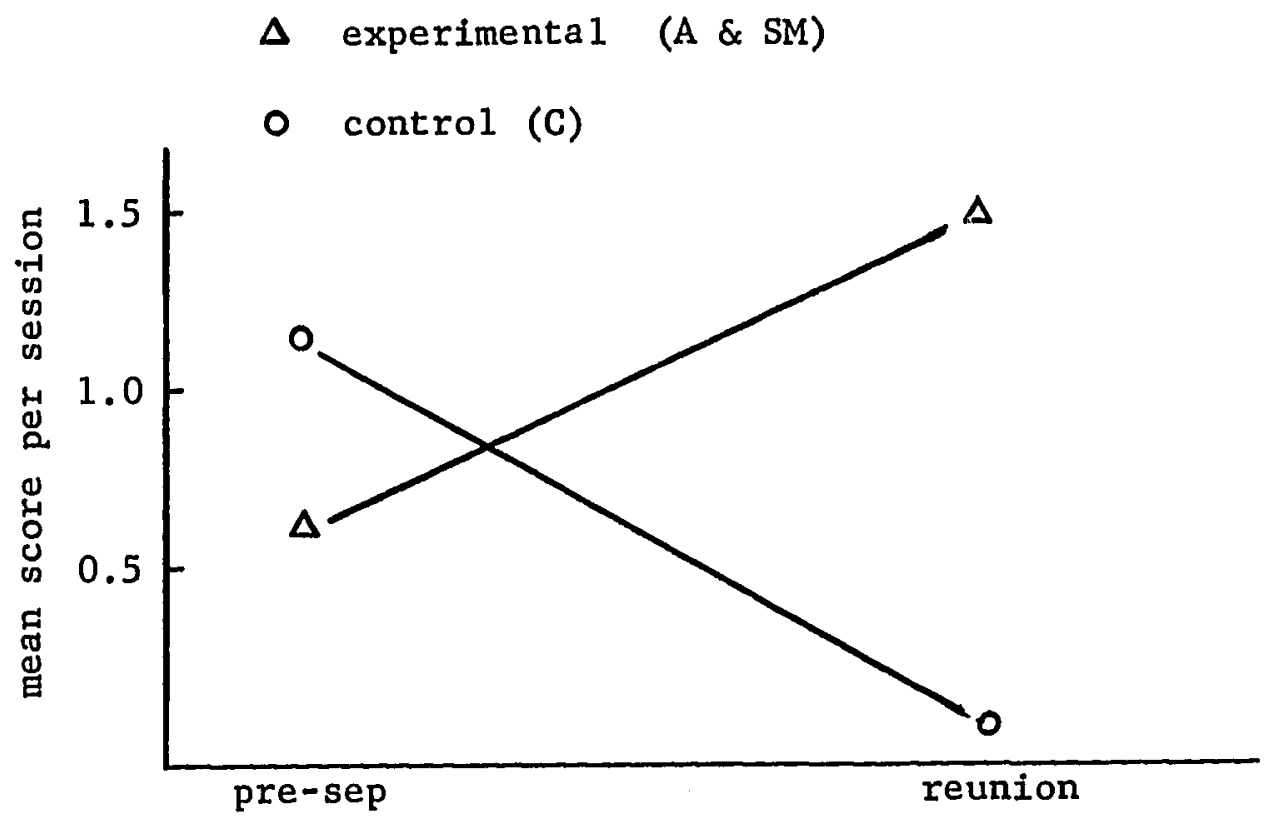

Fig. 14. Mother-infant grooming. Period-wide effects of reunion. 


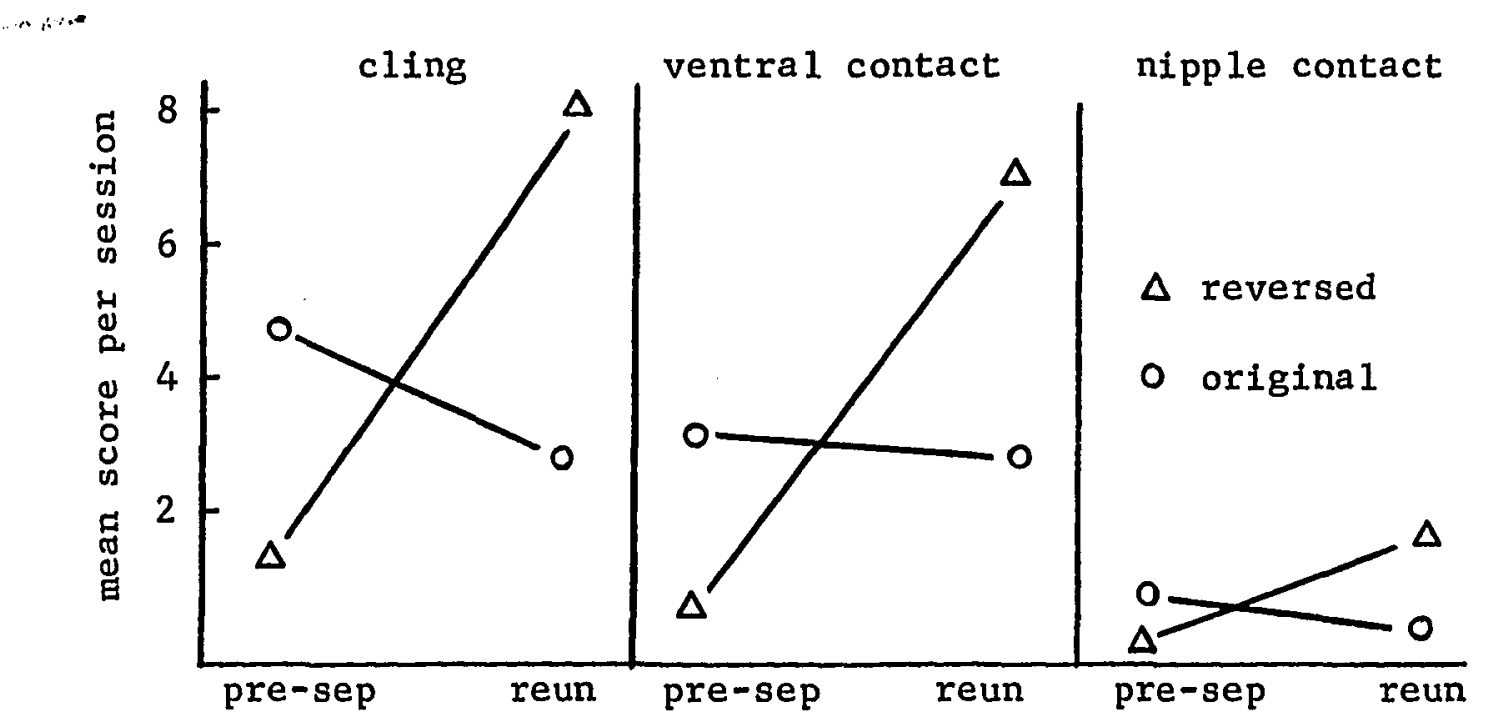

Fig. 15. Infant-mother cling, ventral contact, and nipple contact. Period-wide effects of original vs. reversed home cage return of mothers. 
Behavior of and toward substitute mothers.--Infants in thr SM groups withdrew less from the adult female in the adjacent home cage during separation than did infants in the $\mathrm{C}$ groups whose real mothers were present in period two. Although no other significant differences were found, there was a tendency for real mothers to lipsmack more at $\underline{0}$ and to jaw-drop more at the other infant. There was also a non-significant tendency for infants to touch and make nipple contact more with real mothers. In fact, not a single instance of nipple contact with substitute mothers was observed. 


\section{DISCUSSION}

Results of the present study indicate that maternal separation is indeed stressful to Java infants. The behavior of infants during the separation period was characterized by the almost total obliteration of complex infant social behaviors such as playing and related component behaviors of the infant play pattern. Infant crying (vocal coo) increased and self-mouthing decreased during separation, but behaviors related to more sedentary forms of infant interaction showed only an initial, transient effect. Although a basically similar reaction during separation was seen in the rhesus (Seay et a1., 1962; Seay and Harlow, 1965; Spencer-Booth and Hinde, 1967), in the pigtail (Kaufman and Rosenblum, 1967), and in the patas (Preston et a1., in press), some species-specific differences exist. Patas infants show a sịnificant increase in contact play during separation despite the usual decreases in non-contact and self-play. Preston et a1., (in press) interpreted the difference between patas and macaque reactions to separation in terms of the relationship between maternal roles and peer interaction. Patas mothers are more protective than their Java counterparts and threaten the other infant more during close-quarters play. Separation, therefore, permitted behaviors which previously evoked threat reactions from the mother.

Species differences in the reaction to separation were also evident in the Rosenblum and Kaufman (1968) study. Bonnet macaques 
fail to show a severe reactions to separation if familiar substitutes are provided since their social structure facilitates attachment behavior between infants and adult females other than the mother. It is difficult to make comparisons between the present study and the bonnet data, however, because of differences in apparatus and procedures.

In accord with Bowlby's (1952) views, the reaction of the infants in the present study to separation was due primarily to loss of the specific mother to whom the infants had become attached. Although the presence of an unfamiliar substitute mother in the separation period facilitated recovery during reunion, the effects of separation were nevertheless considerable. In addition, the effects observed during the separation period could not be attributed to the seemingly traumatic nature of the separation procedure, since infants who were separated and immediately reunited with mothers were minimally affected.

Although there were no significant differences in the behavior of substitutes and the specific mothers to whom infants had already become attached, substitutes appeared to be more indifferent toward infants. They seldom threatened the other infant and their attempts to punish infants housed with them, although infrequent, appeared to be more severe. However, it also appeared that there were large individual differences in the behavior of substitutes. One of the substitutes used in Group $\mathrm{SM}_{2}$ frequently embraced the infant housed with her and appeared quite maternal. The infant 
involved appeared to recover somewhat from the effects of separation, and several times attempted to play with the other infant in the group. These attempts resulted in the other infant screeching, feargrimacing, and withdrawing. But evidence obtained in other studies suggests that even highly maternal substitutes could not override the effects of maternal separation. The presence of already familiar (and presumably more materna1) substitute mothers in the Spencer-Booth and Hinde (1967) study did not alleviate the severe reaction of rhesus infants to separation. The effects would probably be similar in Java monkeys since laboratory studies by Seay (1967) have shown a similar pattern of matemal and filial behavior for the two species.

Although some temporary hesitation and disorientation resulted when mothers were returned to reversed home cage locations, all infants were able to recognize and respond differentially to their own mothers after several minutes at most. As in the seay et a1., (1962) and Seay and Harlow (1965) studies, the initial response to reunion was characterized by an intensification of the motherinfant relationship. A similar effect was reported by Ainsworth and Be11 (1970) who noted an increase in proximity-seeking and contactmaintaining behavior in young children during reunion following brief separations. It is apparent that, as Ainsworth and Be11 (1970) pointed out, the attachment between a specific mother-infant pair is not diminished by separation even though attachment behavior had been prevented by the mother's absence.

In the present study, infant playing and most related 
behaviors returned to pre-separation levels shortly after the mother's return. However, intensification of the mother-infant relationship was evident throughout the 3-week reunion period, especially for those infants who had not been provided with substitute mothers during separation. The fact that substitute mothering facilitated recovery in reunion seems contradictory to the rhesus data of Seay et al., (1962) and Seay and Harlow (1965) as compared to that of Spencer-Booth and Hinde (1967). In the Seay studies, all infants were without substitute mothers during the separation period, and the increase in infant-mother and mother-infant positive behaviors in reunion was ephemeral. In the Spencer-Booth and Hinde study, infants remained in contact with already familiar adults. Yet, there was a prolonged intensification of the mother-infant relationship in reunion. A possible explanation is that the sheer complexity of the group situation in the Spencer-Booth and Hinde study may have exacerbated the effects of separation and hindered recovery in reunion. Kaufman and Rosenblum (1967), using the pigtail macaque, also employed a group situation and obtained results similar to Spencer-Booth and Hinde.

As in all the other studies of maternal separation using monkeys, none of the infants in the present study appeared to reach Bowlby's detachment stage. Neither was there any indication of an increase in contact-resisting or contact-avoiding behaviors as recently reported by Ainsworth and Bell (1970) following brief separations of one-year-old human children from their mothers. The 
appearance of a detachment stage in children may very we11 represent a spectes difference between monkeys and humans. The data of Preston et al., (in press) indicates that species differences during reunion exist even among monkeys. Their patas infants showed an increase in peer interaction during reunion rather than an intensification of the mother-infant relationship as seen in macaques. Another possibility, however, is that detachment results when other stressful factors are present in combination with the separation variable. Such confounding factors, such as illness and removal from the home, have been characteristic of studies of maternal separation with human children (Yarrow, 1961). The importance of a change in the physical environment, for example, was also noted in the present study in that the return of mothers to reversed home cages required infants to adapt to a new home cage location. There was virtually no effect of this procedure on $\underline{S}$ s in the control groups, but there was an exacerbation of the already intensified mother-infant relationship for $\underline{S}$ in the experimental groups who had just undergone a stressful separation experience.

Studies of human children have also reported the appearance of aggressive behavior toward the mother during reunion (Robertson, 1955; Heinicke, 1956). Although aggression directed toward the mother has not been reported in any of the studies of maternal separation using monkeys, peer-directed aggression has been seen during the separation and reunion periods (Seay and Harlow, 1965; Preston et al., in press). In the present study, 32 instances of 
peer-directed aggression were noted among six of the 12 infants, but it did not appear to be related to the separation experience. of the 32 Instances, 12 occurred during the pre-separation period, 11 during separation, and 9 during reunion. Furthermore, one of the infants in the present study also exhibited tantrums in which it began screeching loudly and jerking convulsively for no apparent reason. Tantrums had previously been reported by Spencer-Booth and Hinde (1967) during reunion, but in the present study the infant involved exhibited the behavior during the pre-separation period as we11. These data suggest that tantrums, like aggression, are unrelated to the separation experience in Java infants.

Although no indication of detachment or negativism was seen, the results of the present study are generally in accord with the views of Bowlby $(1952 ; 1958 \mathrm{a}, \mathrm{b} ; 1960 \mathrm{a}, \mathrm{b} ; 1961 \mathrm{a}, \mathrm{b})$. Loss and return of the specific mother to whom an infant had become attached were the primary factors responsible for the infants' behavior in separation and reunion respectively. However, Bowlby's Component Instinctual Response theory also assumes there is a genetic bias toward becoming attached and attributes the debilitating effects of separation to the activation of instinctive response systems without termination. An alternative to Bowlby's viewpoint is that of Cairns (1966). Cairns proposed that attachment in mammals is the result of the length of association with an object in a given context and the relative cue weight of the object. Accordingly, an object can become a significant component in the stimulus pattern supporting $\underline{\text { S }}$ 
behavior if there is a continguous association between that object and other environmental or internal events. Attachments to non-social objects can result, but animals are more capable of providing reciprocal stimulation and are more likely to become conditioned. An infant's mother is not only a salient object, but one that is also relevant to the infant's activities and attachment occurs. When the object is removed as in the case of an infant deprived of its mother, associative chains are disrupted and atypical behavior occurs. As pointed out by Seay, Schlottmann, and Thorne (1970), the instinct concept is thus unnecessary and variations within and between species in attachment behavior and in reactions to maternal separation can more readily and more parsimoniously be explained. 
REFERIENCES

Ainsworth, M. D. The effects of maternal deprivation: a review of the findings and controversy in the context of research strategy. In J. Bowlby et al., Maternal care and mental health. Deprivation of maternal care. New York: Schocken Books, 1966.

Ainsworth, M. D. \& Be11, S. M. Attachment, exploration, and separation: illustrated by the behavior of one-year-olds in a strange situation. Child Development, 1970, 41, 49-67.

Andry, R. G. Paternal and maternal roles and delinquency. In J. Bowlby et al., Maternal care and mental health. Deprivation of maternal care. New York: Schocken Books, 1966.

Bowlby, J. Materna1 care and mental health. World Health Organization, monograph series no. 2,1952 .

Bowlby, J. The nature of the child's tie to his mother. Internationa1 Journa1 of Psychoanalysis, 1958, 39, 350-373.

Bowlby, J. (Letter to the editor) Lancet, 1958, $1,480$.

Bowlby, J. Grief and mourning in infancy and early childhood. Psychoanalytic Study of the Child, 1960, 15, 9-52.

Bowlby, J. Separation anxiety. International Journal of Psychoanalysis, $1960,61,89-113$.

Bowlby, J. The Adolf Meyer lecture: childhood mourning and its implications for psychiatry. American Journal of Psychiatry, $1961, \underline{118}, 481-498$.

Bowlby, J. Processes of mourning. Internationa1 Journa1 of Psychoanalysis, $1961,42,317-340$.

Bowlby, J., Ainsworth, M. D., Boston, M., \& Rosenbluth, D. The effects of mother-child separation: a follow-up study. British Journal of Medica1 Psychology. 1956, 29, 211-245.

Cairns, R. B. Attachment behavior of mamma1s. Psychological Review, 1966, 73, 409-426.

Clarke, A. D. B., \& Clarke, A. M. Recovery from the effects of deprivation. Acta Psychologica, 1959, 16, 137-144. 
Hansen, E. W. The development of maternal and infant behavior in the rhesus monkey. Behavior, 1966, 21, 107-149.

Harlow, H. F. \& Zimmerman, R. R. Affectional responses in the rhesus monkey. Science, $1959,130,421-423$.

Heinicke, H. M. Some effects of separating two-year-old children from their parents: a comparative study. Human Relations, $1956, \underline{9}, 105-176$.

Jensen, G. D. \& Tolman, C. W. Mother-infant relationship in the monkey, Macaca nemestrina; the effect of brief separation and mother-infant specificity. Journal of Comparative and Physiological Psychology, 1962, 프, 131-136.

Kaufman, I. C. \& Rosenblum, L. A. Depression in infant monkeys separated from their mothers. Science, 1967, 155, 1030-1031.

Lewis, H. Deprived children: the Mersham experiment: a social and clinical study. London: Oxford University Press, 1954.

Naess, S. Mother-child separation and delinquency. British Journal of Delinquency, 1959, 10, 22-35.

0 'Connor, N. The evidence for the permanently disturbing effects of mother-child separation. Acta Psychologica, 1956, 12, 174-191.

Preston, D. G., Baker, R. P., \& Seay, B. M. Mother-infant separation in patas monkeys, Developmental Psychology, in press.

Prugh, D. G. \& Harlow, R. G. "Masked deprivation" in infants and young children. In $\mathrm{J}$. Bowlby et al., Maternal care and mental health. Deprivation of maternal care. New York: Schocken Books, 1966.

Robertson, J. Some responses of young children to loss of maternal care. Nursing Times, 1955, 49, 382-386.

Rosenblum, L. A. \& Kaufman, I. C. Variations in infant development and response to maternal loss in monkeys. American Journal of Orthopsychiatry, $1968, \underline{38}, 418-426$.

Seay, B. M. Maternal behavior in Macaca irus. Paper presented at the meeting of the Southeastern Psychological Association, Atlanta, April 1967.

Seay, B. M., Hansen, E., \& Harlow, H. F. Mother-infant separation in monkeys. Journal of Child Psychology and Psychiatry, 1962 , 3, 123-132. 
Seay, B. \& Harlow, H. F. Maternal separation in the rhesus monkey. Journa1 of Nervous and Menta1 Disease, 1965, 140, 434-441.

Seay, B., Schlottmann, R. S., \& Thorne, B. M. Maternal and filia? behavior in monkeys. Developmental Psychology, 1970, 2 , $\mathrm{XXX}-\mathrm{XXX}$.

Spence, K. W. Reáctions des meres chimpanzés a l'egard des enfants chimpanzés après séparation. Journal de psychologie normale et pathologique, $1937,34,445-493$.

Spencer-Booth, $Y$. \& Hinde, R. A. The effects of separating rhesus monkey infants from their mothers for six days. Journal of Child Psychology and Psychiatry, 1967, I, 179-197.

Stott, D. H. The effects of separation from the mother in early life. Lancet, $1956, \underline{270}, 624-628$.

Thorne, B. M., Schlottmann, R. S., \& Seay, B. Single animal observation vs. pair observation in Macaca irus. Journal of Genetic Psychology, 1969, 115; 17-32.

Wooton, B. A social scientist's approach to maternal deprivation. In J. Bowlby et a1., Maternal care and mental health. Deprivation of maternal care. New York: Schocken Books, 1966.

Yarrow, L. C. Maternal deprivation: toward an empirical and conceptual re-evaluation. Psychological Bulletin, 1961, 58, 459-490. 


\section{APPENDICES}

Code:

$$
\begin{aligned}
A= & \text { treatment during period two } \\
\mathrm{A}_{1}= & \text { infants alone following removal of real mothers } \\
\mathrm{A}_{2}= & \text { infants with unfamiliar substitute mothers following } \\
& \quad \text { removal of real mothers } \\
\mathrm{A}_{3}= & \text { infants with real mothers following removal and } \\
& \text { immediate return of latter }
\end{aligned}
$$

$B=$ treatment during period three

$$
\begin{aligned}
& \mathrm{B}_{1}=\text { mothers returned to original home cage locations } \\
& \mathrm{B}_{2}=\text { mothers returned to reversed home cage locations }
\end{aligned}
$$

$$
\begin{aligned}
\mathrm{C}=\text { periods } & \\
\mathrm{C}_{1} & =\text { pre-separation (period one) } \\
\mathrm{C}_{2} & =\text { separation (period two) } \\
\mathrm{C}_{3} & =\text { reunion (period three) }
\end{aligned}
$$




\section{APPENDIX I}

Orthogonal Coefficients Used in

Analysis of Period-Wide Effects of Separation and Reunion on Infant-Infant and Infant Non-Social Behavior 
C Summary Table

$\mathrm{c}_{1}$

$+1$
$\mathrm{C}_{2}$

$-1$
$\mathrm{C}_{3}$

$$
0
$$


AC Summary Table

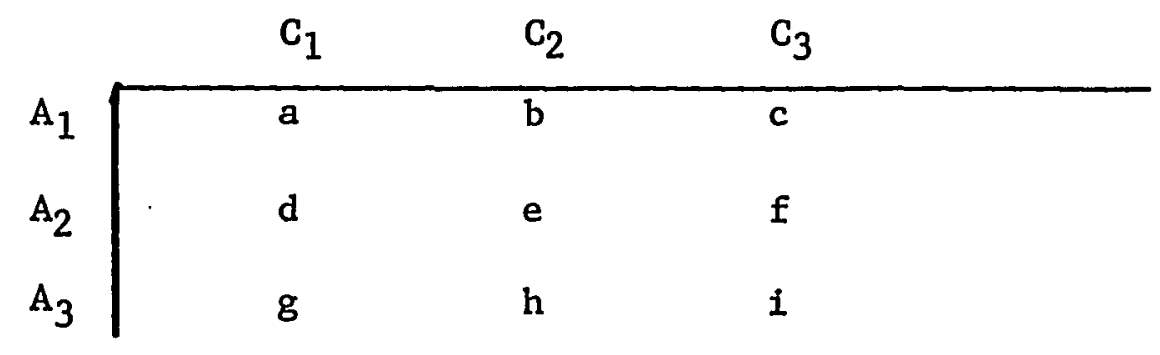

$\begin{array}{rrrrrrrrr}\mathrm{a} & \mathrm{b} & \mathrm{c} & \mathrm{d} & \mathrm{e} & \mathrm{f} & \mathrm{g} & \mathrm{h} & \mathrm{i} \\ +1 & -1 & 0 & +1 & -1 & 0 & -2 & +2 & 0 \\ +1 & -1 & 0 & -1 & +1 & 0 & 0 & 0 & 0 \\ 0 & 0 & +1 & 0 & 0 & +1 & 0 & 0 & -2 \\ 0 & 0 & +1 & 0 & 0 & -1 & 0 & 0 & 0\end{array}$


BC Summary Table

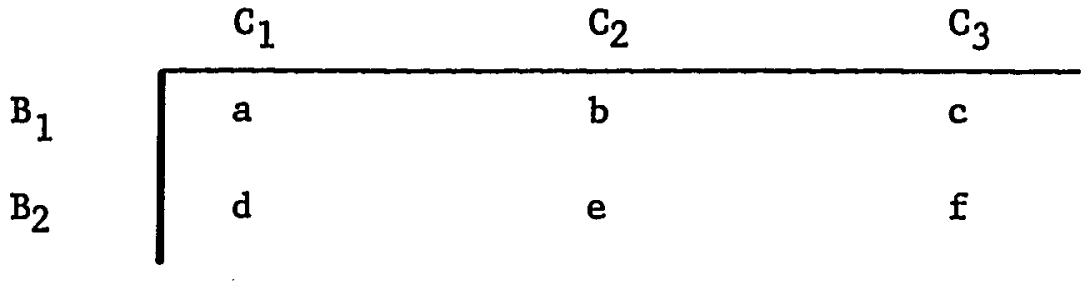

$\begin{array}{rrrrrr}\mathrm{a} & \mathrm{b} & \mathrm{c} & \mathrm{d} & \mathrm{e} & \mathrm{f} \\ 0 & +1 & -1 & 0 & -1 & +1 \\ +1 & 0 & 0 & -1 & 0 & 0\end{array}$


ABC Summary Table

\begin{tabular}{|c|c|c|c|}
\hline & $\mathrm{C}_{1}$ & $\mathrm{C}_{2}$ & $\mathrm{C}_{3}$ \\
\hline $\mathrm{A}_{1}$ & $\mathbf{a}$ & $\mathrm{b}$ & c \\
\hline $\mathrm{A}_{2}$ & $\mathrm{~d}$ & e & $f$ \\
\hline $\mathrm{A}_{3}$ & $\mathbf{g}$ & $\mathrm{h}$ & $i$ \\
\hline $\mathrm{A}_{1}$ & $\mathbf{j}$ & $\mathbf{k}$ & 1 \\
\hline $\mathrm{A}_{2}$ & $\mathbf{m}$ & $\mathbf{n}$ & 0 \\
\hline $\mathrm{A}_{3}$ & $\mathrm{P}$ & $\mathrm{q}$ & $\mathbf{r}$ \\
\hline
\end{tabular}

$$
\begin{array}{rrrrrrrrrrrrrrrrrr}
\mathrm{a} & \mathrm{b} & \mathrm{c} & \mathrm{d} & \mathrm{e} & \mathrm{f} & \mathrm{g} & \mathrm{h} & \mathrm{i} & \mathrm{j} & \mathrm{k} & 1 & \mathrm{~m} & \mathrm{n} & 0 & \mathrm{p} & \mathrm{q} & \mathrm{r} \\
0 & +1 & -1 & 0 & +1 & -1 & 0 & 0 & 0 & 0 & -1 & +1 & 0 & -1 & +1 & 0 & 0 & 0 \\
+1 & -1 & 0 & +1 & -1 & 0 & 0 & 0 & 0 & +1 & -1 & 0 & +1 & -1 & 0 & 0 & 0 & 0 \\
0 & 0 & 0 & 0 & 0 & 0 & +1 & -1 & 0 & 0 & 0 & 0 & 0 & 0 & 0 & +1 & -1 & 0 \\
0 & 0 & 0 & 0 & 0 & 0 & 0 & +1 & -1 & 0 & 0 & 0 & 0 & 0 & 0 & 0 & -1 & +1
\end{array}
$$




\begin{abstract}
APPENDIX II
Orthogonal Coefficients Used

in Analysis of Immediate Effects of Separation

on Infant-Infant and Infant Non-Social Behavior
\end{abstract}


C Summary Table

Last $\mathrm{C}_{1}$

$+1$
First $\mathrm{C}_{2}$

$-1$ 


\section{AC Summary Table}

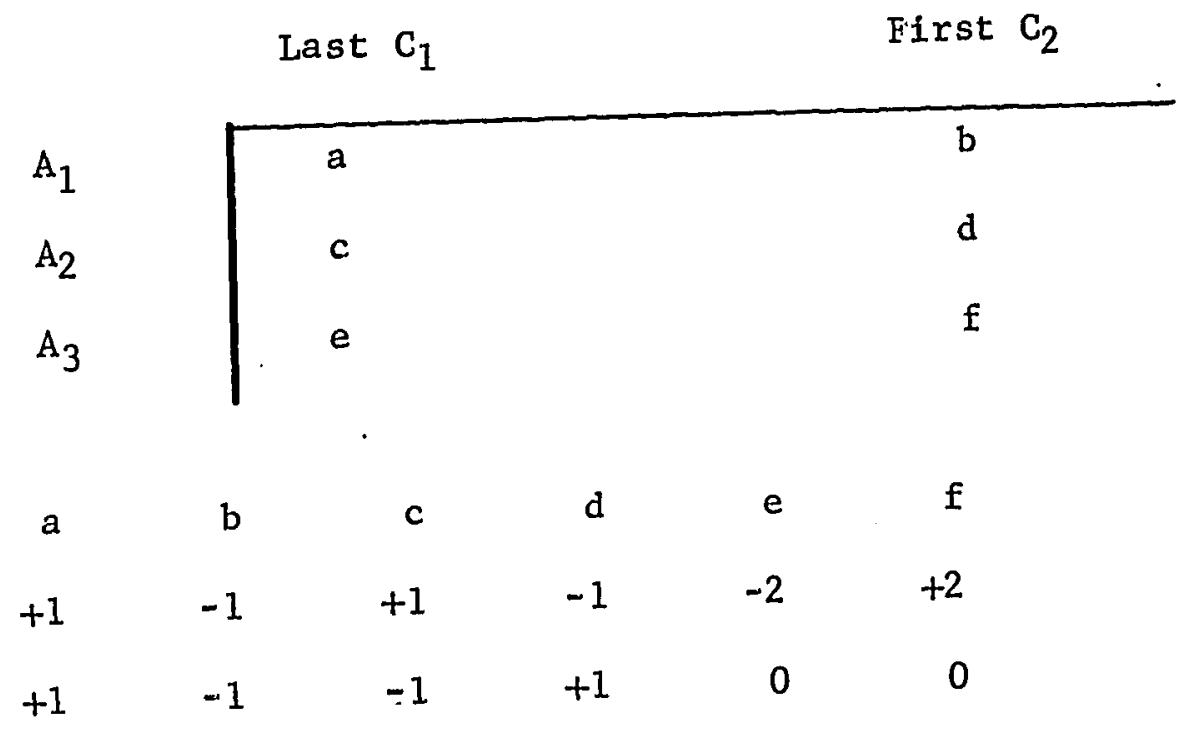


APPENDIX III

Orthogonal Coefficients Used

in Analysis of Immediate Effects of Reunion

on al1 behaviors

and in Analysis of Period-Wide Effects of Reunion

on Mother and Mother-Related Behaviors 
C Summary Table

Last $\mathrm{C}_{1}$

First $C_{3}$

$+1$

$-1$ 
AC Summary Table

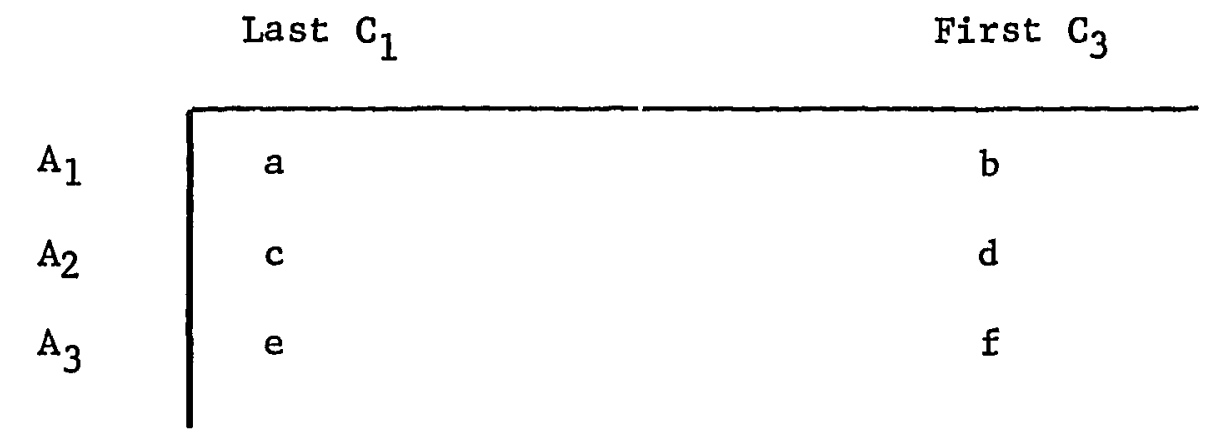

$\begin{array}{rrrrrr}a & b & c & d & e & f \\ +1 & -1 & +1 & -1 & -2 & +2 \\ +1 & -1 & -1 & +1 & 0 & 0\end{array}$


BC Summary Table

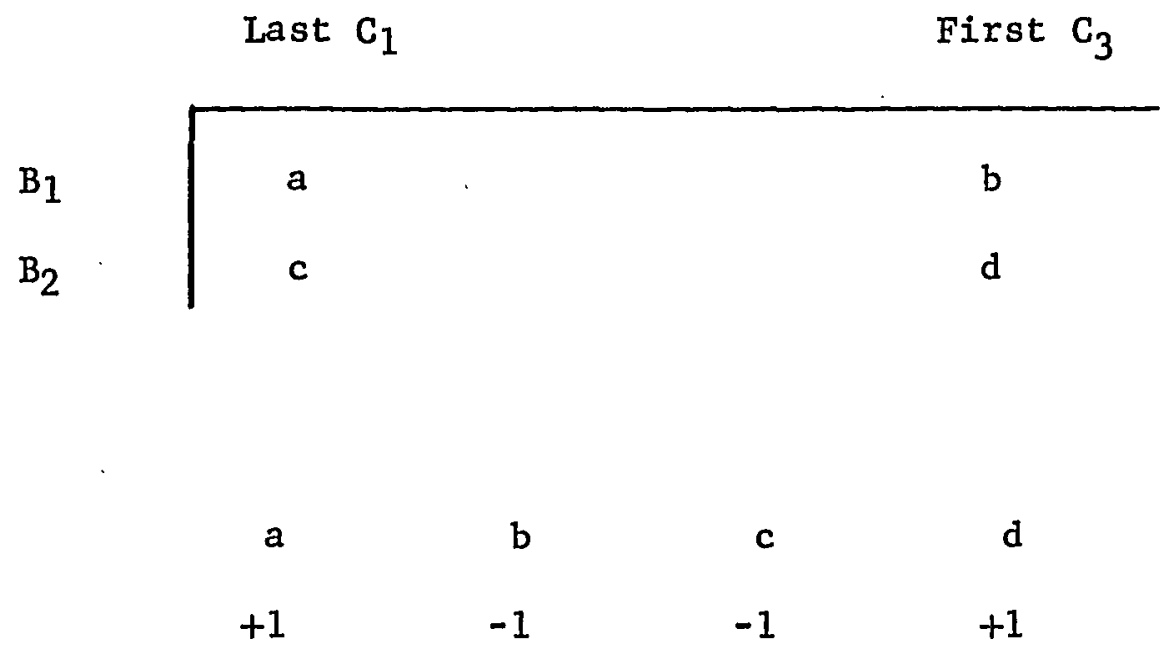


ABC Summary Table

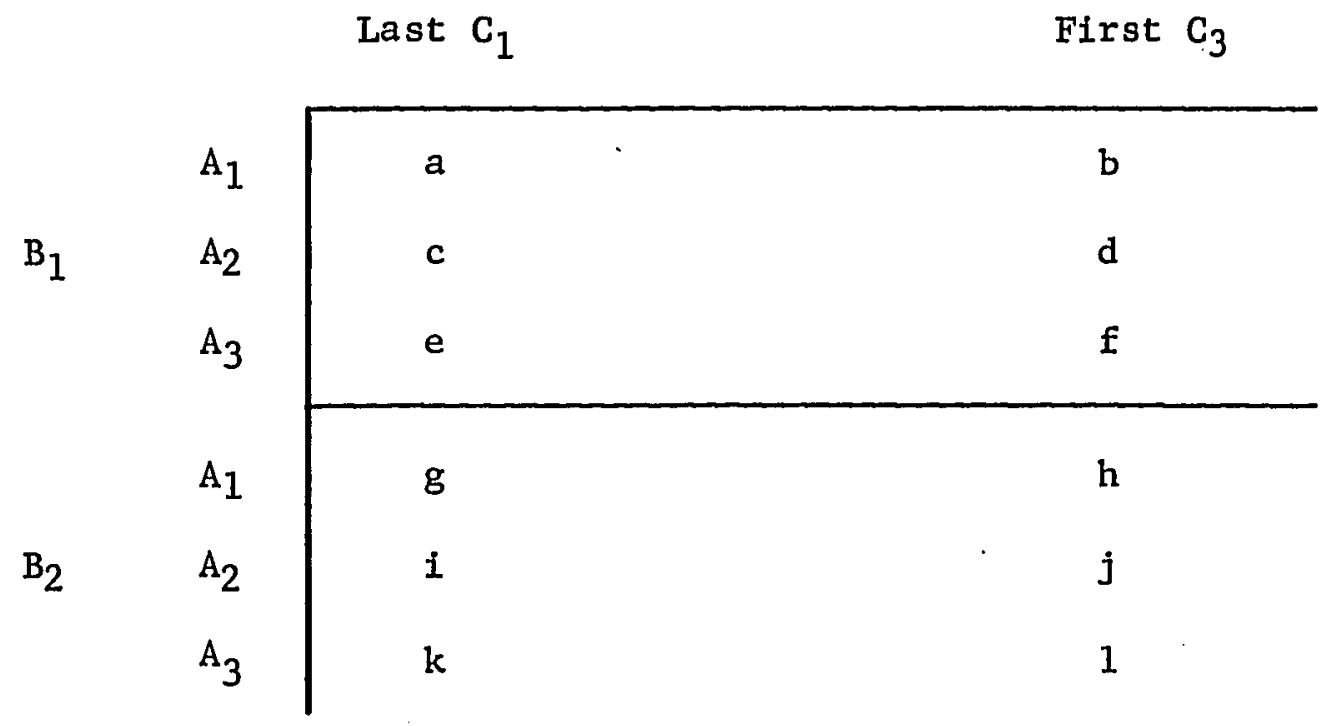

$\begin{array}{rrrrrrrrrrrr}\mathrm{a} & \mathrm{b} & \mathrm{c} & \mathrm{d} & \mathrm{e} & \mathrm{f} & \mathrm{g} & \mathrm{h} & \mathrm{i} & \mathrm{j} & \mathrm{k} & 1 \\ +1 & -1 & +1 & -1 & 0 & 0 & -1 & +1 & -1 & +1 & 0 & 0 \\ 0 & 0 & 0 & 0 & +1 & -1 & 0 & 0 & 0 & 0 & -1 & +1\end{array}$


Robert Stanislaus Schlottmann was born in New Orleans, Louisiana on October 22, 1937. He graduated from De La Salle High School in New Orleans in 1955. He was employed for several years before attending Louisiana State University in New Orleans where he majored in psychology and received his bachelor's degree in 1962 . After working with mentally retarded children for a year, he attended Tulane University and received his master's degree in psychology in 1965. He continued his graduate work at LSU's main campus in Baton Rouge in clinical psychology and completed his internship at the University of Texas' Southwestern Medical School at Dallas. While a student at LSU, he worked with Dr. Bill Seay as a research assistant in the LSU Primate Laboratory. He is married to the former Miss Carol Hellbach and has one child, Robert Brien, eleven months old. 
Candidate: Robert Stanislaus Schlottmann

Major Field: Psychology

Title of Thesis: Mother-infant separation in the Java monkex (Macaca irus)

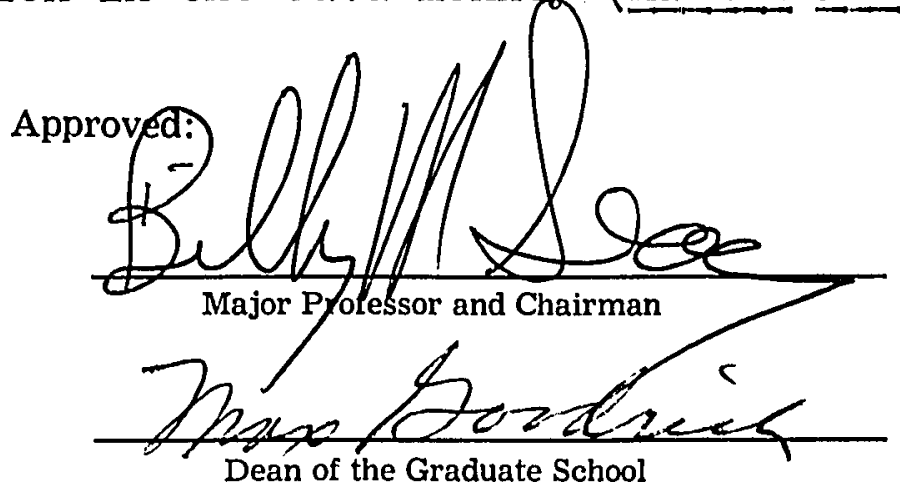

EXAMINING COMMITTEE:

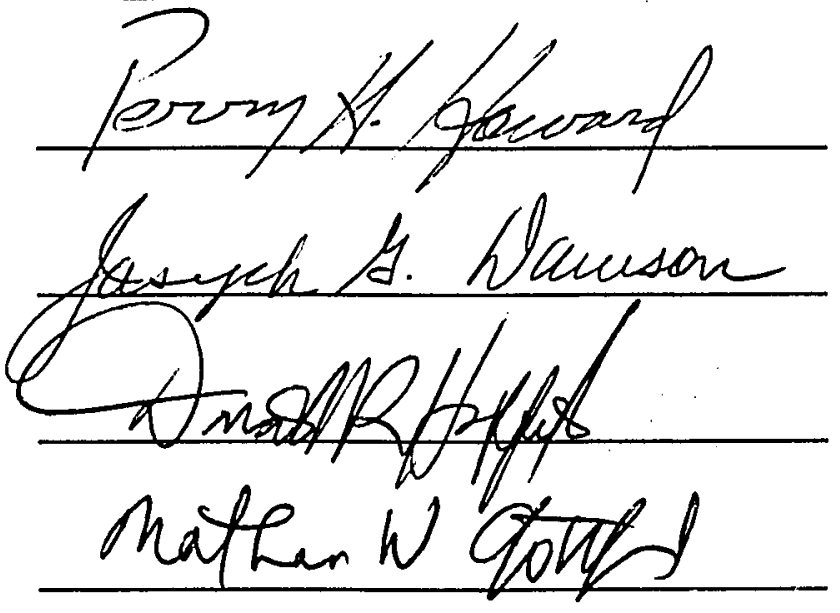

Date of Examination: 